\title{
Impact of pollution controls in Beijing on atmospheric oxygenated volatile organic compounds (OVOCs) during the 2008 Olympic Games: observation and modeling implications
}

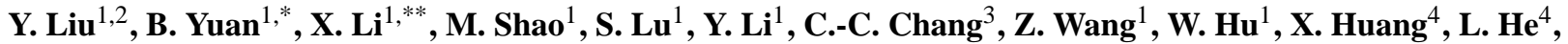 \\ L. Zeng ${ }^{1}$, M. Hu ${ }^{1}$, and T. Zhu ${ }^{1}$ \\ ${ }^{1}$ State Joint Key Laboratory of Environmental Simulation and Pollution Control, College of Environmental \\ Sciences and Engineering, Peking University, Beijing, China \\ ${ }^{2}$ Chinese Research Academy of Environmental Sciences, Beijing, China \\ ${ }^{3}$ Research Center for Environmental Changes, Academia Sinica, Taipei, Taiwan \\ ${ }^{4}$ School of Environment and Energy, Peking University Shenzhen Graduate School, Shenzhen, China \\ * now at: Earth System Research Laboratory, National Oceanic and Atmospheric Administration \\ (NOAA), Boulder, Colorado, USA \\ ** now at: Institut für Energie- und Klimaforschung Troposhäre (IEK-8), Forschungszentrum Jülich, \\ Jülich, Germany
}

Correspondence to: M. Shao (mshao@pku.edu.cn)

Received: 3 August 2014 - Published in Atmos. Chem. Phys. Discuss.: 17 October 2014

Revised: 15 February 2015 - Accepted: 2 March 2015 - Published: 18 March 2015

\begin{abstract}
Oxygenated volatile organic compounds (OVOCs) are important products of the photo-oxidation of hydrocarbons. They influence the oxidizing capacity and the ozoneforming potential of the atmosphere. In the summer of 2008, 2 months of emission restrictions were enforced in Beijing to improve air quality during the Olympic Games. Observational evidence reported in related studies that these control measures were efficient in reducing the concentrations of primary anthropogenic pollutants $\left(\mathrm{CO}, \mathrm{NO}_{\mathrm{x}}\right.$ and non-methane hydrocarbons, i.e., NMHCs) by $30-40 \%$. In this study, the influence of the emission restrictions on ambient levels of OVOCs was explored using a neural network analysis with consideration of meteorological conditions. Statistically significant reductions in formaldehyde (HCHO), acetaldehyde $\left(\mathrm{CH}_{3} \mathrm{CHO}\right)$, methyl ethyl ketone (MEK) and methanol were found to be 12.9, 15.8, 17.1 and $19.6 \%$, respectively, when the restrictions were in place. The effect of emission controls on acetone was not detected in neural network simulations, probably due to pollution transport from surrounding areas outside Beijing. Although the ambient levels of most NMHCs were reduced by $\sim 35 \%$ during the full control period, the emission ratios of reactive alkenes and aromatics
\end{abstract}

closely related to automobile sources did not present much difference $(<30 \%)$. A zero-dimensional box model based on the Master Chemical Mechanism version 3.2 (MCM3.2) was applied to evaluate how OVOC production responds to the reduced precursors during the emissions control period. On average, secondary $\mathrm{HCHO}$ was produced from the oxidation of anthropogenic alkenes (54\%), isoprene (30\%) and aromatics $(15 \%)$. The importance of biogenic sources for the total HCHO formation was almost on par with that of anthropogenic alkenes during the daytime. Anthropogenic alkenes and alkanes dominated the photochemical production of other OVOCs such as acetaldehyde, acetone and MEK. The relative changes of modeled $\mathrm{HCHO}, \mathrm{CH}_{3} \mathrm{CHO}$, methyl vinyl ketone and methacrolein (MVK + MACR) before and during the pollution controlled period were comparable to the estimated reductions in the neural network, reflecting that current mechanisms can largely explain secondary production of those species under urban conditions. However, it is worth noting that the box model overestimated the measured concentrations of aldehydes by a factor of 1.4 1.7 without consideration of loss of aldehydes on aerosols, and simulated MEK was in good agreement with the mea- 
surements when primary sources were taken into consideration. These results suggest that the understanding of the OVOCs budget in the box model remains incomplete, and that there is still considerable uncertainty in particular missing sinks (unknown chemical and physical processes) for aldehydes and absence of direct emissions for ketones.

\section{Introduction}

Oxygenated volatile organic compounds (OVOCs), such as aldehydes, ketones and alcohols, are mostly produced in the atmosphere by the oxidation of biogenic, anthropogenic hydrocarbons and other organic species (Finlayson-Pitts and Pitts, 2000), and also directly emitted by vegetation (Park et al., 2013), biomass burning (Yokelson et al., 2009; Mason et al., 2001; Andreae and Merlet, 2001), fossil fuel combustion (Schauer et al., 1999, 2002) and industries (Singh et al., 1994). They are lost through oxidation by OH, photolysis, and deposition/surface uptake. Aircraft measurements showed that the vertical distribution $(0-12 \mathrm{~km})$ of the total concentrations of oxygenated organics was 2-5 times as abundant as the sum of $\mathrm{C}_{2}-\mathrm{C}_{8}$ non-methane hydrocarbons (NMHCs) at all altitudes in the remote Pacific troposphere (Singh et al., 2001). Formaldehyde (HCHO) and other oxygenated hydrocarbons dominated the total $\mathrm{OH}$ loss with VOCs (volatile organic compounds) in clean air masses (Goldan et al., 2004). In polluted atmospheres the interaction of primary and secondary VOCs is closely coupled with the formation of ozone and secondary organic aerosols (SOA). And usually OVOCs serve as intermediate products in these oxidation processes, which helps to estimate the formation potential of ozone (Shao et al., 2011) and other products. And OVOCs also affect the oxidizing capacity of the atmosphere. Some previous studies found that carbonyls are one of the most important radical sources, especially for the wintertime in polluted urban environments (Emmerson et al., 2005). Accordingly, it is essential to understand the sources, sinks and chemistry of OVOCs quantitatively, while the role of OVOCs in heavily polluted regions remains largely unexplored partly due to the lack of reliable observations of them.

Beijing, the capital of China and one of the most populous megacities in the world, is located in northern China. Accompanied with the rapid population growth and economic expansion, severe air pollution in Beijing has attracted global attention. The city has been known for its increasing ozone concentration (Parrish and Zhu, 2009; Shao et al., 2009) and hazy skies (Chan and Yao, 2008). In preparation for the 2008 Summer Olympics and to clean up the city's air, Beijing imposed a number of pollution control measures during the games. Thus, coordinated observations on such a restricted occasion create a valuable opportunity for studying how OVOCs respond to the emission reductions, testing and refining the current knowledge of formation pathways of secondary OVOCs under polluted conditions.

After Beijing was selected as the host of the 2008 Summer Olympics, the Beijing government started to implement a series of long-term emission control regulations, such as the closure of heavy polluting industries (chemical factories, cement plants, steel manufacturing, etc.) in the southeast of the city, relocating nearly 200 factories out of the Beijing area; also tightening the vehicle emission and fuel quality standards, and accelerating the retirement of old vehicles. More stringent, short-term measures were put into effect from 1 July to 20 September 2008 such as temporarily halting industrial production, suspending construction and evaporative emissions. Nearly 2 million vehicles were banned from the roads step by step (UNEP, 2009): (1) a total of 350000 yellow-labeled vehicles with high emissions were not allowed to enter the city starting from $1 \mathrm{July}$; (2) $50 \%$ of privately owned vehicles were restricted to run on alternate days (based on their license plate numbers) in the metropolis and $70 \%$ of government-owned vehicles were halted from operating from 21 July to 20 September, which is a so-called "full control period". As a result, the traffic emissions on VOCs, $\mathrm{CO}, \mathrm{NO}_{\mathrm{x}}$, and particulate matter (PM) were estimated to be reduced by $50 \%$ (Wang et al., 2010b).

The 2 months of emission restrictions had a noticeable impact on major pollutants directly emitted from fuel combustions, which have been validated by on-road measurements (Wang et al., 2009a, b; Wang and Xie, 2009), groundlevel monitoring (Wang et al., 2010a, c; Chou et al., 2011; Zhang et al., 2009) and satellite-based observations (Witte et al., 2009; Worden et al., 2012; Lyapustin et al., 2011). Satellite measurements over Beijing showed a $43 \%$ reduction of tropospheric column $\mathrm{NO}_{2}$ during the games (Witte et al., 2009), and a $32 \%$ reduction in CO for 2008 with respect to 2007 was estimated from MOPITT (Measurement of Pollution in the Troposphere) satellite retrievals (Worden et al., 2012). Wang et al. (2009a) found a dramatic decrease of primary pollutants from on-road measurements, by up to $54 \%$ for $\mathrm{CO}, 41 \%$ for $\mathrm{NO}_{\mathrm{x}}$ and $66 \%$ for aromatics (benzene, toluene, ethylbenzene and xylenes, BTEX). And Wang et al. (2010a) reported the averaged mixing ratios of NMHCs near the Olympic Stadium during the games were reduced by $35 \%$, compared with the concentrations measured in June (before the restrictions). The monthly concentrations of NO, $\mathrm{NO}_{2}$ and $\mathrm{CO}$ were reduced by $76.8,29.7$ and $27.8 \%$ in $\mathrm{Au}-$ gust 2008 compared to previous years for the same month (Chou et al., 2011). In contrast, the observed mixing ratio of $\mathrm{O}_{3}$ increased by $16 \%$ during the full control, compared to the period prior to 20 July (Wang et al., 2010c). The higher levels of ozone were influenced by the declined $\mathrm{O}_{3}-\mathrm{NO}$ titration and the shift in different $\mathrm{O}_{3}$ formation regimes (Chou et al., 2011), changes in weather conditions, or/and by the transport of photochemical plumes from the surrounding areas to Beijing (Wang et al., 2010c). So, the influence of control measures on secondary pollutants still needs more investigation. 
The limited OVOCs data sets available in Beijing suggest that the ambient levels of carbonyls were observed to be 35 times higher than the levels in Hong Kong, about $35 \%$ of those in Mexico City (Pang and Mu, 2006), and comparable to those in Rio de Janeiro, Brazil (Grosjean et al., 2002). In summer, about $60-70 \%$ of aldehydes in Beijing were associated with the photochemical oxidation of anthropogenic and biogenic VOCs, and $10-15 \%$ of them were attributed to the primary emission from anthropogenic sources (Liu et al., 2009). For ketones and alcohols, anthropogenic primary emissions were shown to be the largest contributor (Liu et al., 2009; Yuan et al., 2012). The 2008 summer provides the opportunity to estimate the impact of reduced emissions on ambient OVOCs. In this study, firstly a neural network approach was used to link VOC mixing ratios to meteorological conditions, which helps to ascertain that the observed changes in VOCs are significant due to the emission restrictions, rather than variations caused by different meteorological conditions. Secondly, a box model using the Master Chemical Mechanism (MCM) was employed to investigate secondary formation of OVOCs during the full control period, in particular, of two most abundant aldehydes (formaldehyde, acetaldehyde), two ketones (acetone and MEK) and unique oxidation products of isoprene chemistry (MVK + MACR). Moreover, this study also aims to quantify the changes of secondary OVOCs by the existing mechanisms, responding to the reduced precursors (NMHCs) and other pollutants $\left(\mathrm{CO}, \mathrm{NO}, \mathrm{NO}_{2}, \mathrm{O}_{3}\right)$, and to analyze the similarity or discrepancy between the measured and modeled changes in OVOCs before and during the full control.

\section{Methodologies}

\subsection{Monitoring sites and experimental methods}

As part of the CAREBEIJING 2008 campaign, the measurements of VOCs and other air pollutants $\left(\mathrm{CO}, \mathrm{NO}_{\mathrm{x}}, \mathrm{O}_{3}\right.$, etc $)$ were conducted at an intensive observation site on the campus of Peking University (PKU) from 3 July to 27 August 2008. The PKU site $\left(39.99^{\circ} \mathrm{N}, 116.31^{\circ} \mathrm{E}\right)$ was located in the northwest of downtown Beijing, which has been considered to be representative of a typical urban environments with different mixtures of high density traffic, commercial, residential, and electronic companies (Liu et al., 2009; Cheng et al., 2008; Song et al., 2007). The air inlets for the instruments were set up on the top of a six-story building ( $\sim 25 \mathrm{~m}$ a.g.l). Three online techniques were used to quantify NMHCs and OVOCs during the campaign, including a proton-transferreaction mass spectrometer (PTR-MS), a gas chromatograph with mass spectrometer and flame ionization detector (GCMS/FID) and a Hantzsch fluorimetric monitor.

\subsubsection{Online measurements for NMHCs and OVOCs}

A high-sensitivity PTR-MS (Ionicon Analytik, Innsbruck, Austria) was used for ambient measurements of selected NMHCs and OVOCs. This technique ionizes VOC molecules by transferring protons $\left(\mathrm{H}^{+}\right)$from protonated water ions $\left(\mathrm{H}_{3} \mathrm{O}^{+}\right)$in a drift tube, followed by a quadrupole mass spectrometer detection of the product ions (Lindinger et al., 1998; de Gouw and Warneke, 2007). The air sample was drawn through an $8 \mathrm{~m}$ long perfluoroalkoxy (PFA) tube $(0.25 \mathrm{in}$. OD $\times 0.156$ in. ID) into the gas-handling system by a diaphragm pump at the flow rate of $2-3 \mathrm{slpm}$. A small flow of 220 $240 \mathrm{sccm}$ was branched from the main flow to the PTR-MS. A $2.0 \mu \mathrm{m}$ pore-size $47 \mathrm{~mm}$ PTFE (polytetrafluorethylene) filter at the inlet was used to remove particles from the sample flow.

The operating parameters of PTR-MS used herein are similar to those described previously in Yuan et al. (2010a). The instrument was operated at $2.3 \mathrm{mbar}$ drift tube pressure and $600 \mathrm{~V}$ drift voltage, 35 masses were sampled with the time resolution of $160 \mathrm{~s}$. Instrument background signals were measured every 35 cycles $(\sim 1.5 \mathrm{~h})$ by switching the sample air to an activated charcoal trap for 5 cycles $(\sim 13 \mathrm{~min})$. Target ions with the dwell time of $5 \mathrm{~s}$ for each cycle included OVOCs such as methanol $(m / z=33)$, acetaldehyde $(m / z=45)$, acetone $(m / z=59), \operatorname{MVK}+\operatorname{MACR}(m / z=$ 71 ), methyl ethyl ketone (MEK, $m / z=73$ ); aromatics such as benzene $(\mathrm{m} / \mathrm{z}=79)$, toluene $(\mathrm{m} / \mathrm{z}=93)$, styrene $(\mathrm{m} / \mathrm{z}=$ 105), $\mathrm{C} 8$ aromatics $(m / z=107)$ and $\mathrm{C} 9$ aromatics $(\mathrm{m} / z=$ $121)$; isoprene $(m / z=69)$ and acetonitrile $(m / z=42)$. The PTR-MS was calibrated every week using a commercial TO15 gas standard (Air Environmental Inc. Denver, USA) at seven concentration levels ranging from 1 to $15 \mathrm{ppb}$. For most species, the detection limits were between 23 and $60 \mathrm{pptv}$, except methanol (141 pptv), acetone (148 pptv) and MEK (110 pptv). The relative errors of the PTR-MS measurements decrease with the mixing ratios of target species, as shown in Fig. S1, and the precisions of all detected species were below $5 \%$ at the level of $1 \mathrm{ppbv}$.

An automated GC-MS/FID system with two columns and two detectors was deployed by the Research Center for Environmental Changes (RCEC), Academia Sinica, Taiwan, which was used to measure $\mathrm{C}_{2}-\mathrm{C}_{4}$ hydrocarbons and $\mathrm{C}_{5}-$ $\mathrm{C}_{11}$ hydrocarbons simultaneously. Technical details for this instrument were presented in Chou et al. (2011). A total of 65 NMHCs were quantified hourly during the full control period (24 July-27 August), the precision for most of the species was within $2 \%$ and the limits of detection were below 30 pptv.

The comparison between the PTR-MS and GC-MS data showed a good agreement for aromatics (benzene, toluene, C8 aromatics and C9 aromatics) during the campaign, as shown in Fig. S2a, with the slopes varying between 0.86 and 1.21 and the correlation coefficients larger than 0.89 . The isoprene concentrations measured by PTR-MS were systemati- 
cally higher than those measured by GC-MS, particularly for the mixing ratios lower than 1 ppbv, shown in Fig. S2b, possibly because signals at $m / z 69$ detected by PTR-MS were influenced by some interferences from pentanal, methylbutanal, pentenol (de Gouw et al., 2003) and cycloalkanes (Yuan et al., 2014). It should be noted that the artifact of PTR-MS measurements on isoprene leads to an additional background in anthropogenic-emission-dominated areas. So, the isoprene data from the GC-MS is used in the following model calculations.

$\mathrm{HCHO}$ was measured by an online Hantzsch fluorimetric monitor at the time resolution of $10 \mathrm{~min}$. The instrument is described in previous publications (Dasgupta et al., 2005; Li et al., 2010) and was based on sensitive wet chemical fluorimetric detection of HCHO. A diffusion scrubber was designed to strip and collect $\mathrm{HCHO}$ from the gas phase into the liquid phase. The detection limit for $\mathrm{HCHO}$ was within 100 pptv, and the precision was below $10 \%$.

\subsubsection{Measurements for other air pollutants and parameters}

A comprehensive set of instruments was installed at the PKU site to monitor the air quality. $\mathrm{CO}$ was measured by a nondispersive infrared sensor (NDIR) with an integration time of 1 min (48 CTLE, Thermo Environmental Instruments, TEI, USA). Zero calibrations were done every $2 \mathrm{~h}$ and span calibrations were performed at midnight (00:00-1:00 LT) each day during the campaign. Ozone was measured by a UV absorption detector (Model 49i, TEI). NO was measured using a $\mathrm{NO} / \mathrm{O}_{3}$ chemiluminescence analyzer (Model 42iTL, TEI), with the instrument sequentially measuring $\mathrm{NO}_{2}$ through a photolytic converter.

HONO was measured using an online stripping coil sampler/ion chromatography (IC) system at the time resolution of $15 \mathrm{~min}$. The instrument has a detection limit of $8 \mathrm{ppt}$ with an uncertainty of $7 \%$, other technical details were presented in Cheng et al. (2013).

For aerosol measurements at the site, particle size distributions from 3 to $900 \mathrm{~nm}$ (mobility diameter) were measured by a TDMPS (twin differential mobility particle sizer) system with 10 min time resolution, as presented in Wang et al. (2011). An Aerodyne HR-TOF-AMS (high-resolution time-of-flight aerosol mass spectrometer) was deployed to measure chemical compositions of PM1. A detailed description of the system was shown in Huang et al. (2010).

A meteorological station was operated simultaneously to monitor meteorological parameters (temperature, $\mathrm{RH}$, pressure, wind speed and wind direction) on the campus, which was about $400 \mathrm{~m}$ away from the air quality intensive site. The photolysis frequencies of $\mathrm{O}^{1} \mathrm{D}$ and $\mathrm{NO}_{2}$ were measured at the PKU site by two filter radiometers (Bohn et al., 2008) with a time resolution of $5 \mathrm{~s}$. The uncertainties of $J$ values were within $10 \%$.

\subsection{Methodology for neutral network}

The temporal variation of VOC concentrations at a receptor site reflects a combination of changes in emission location and strength, meteorological conditions, chemical loss and secondary formation. Previous studies indicated that meteorological conditions, especially local wind speed and direction, played an important role in shaping the air quality of Beijing (Wu et al., 2008). We cannot quantify the influence of emission restrictions on ambient VOCs by simply comparing their levels during the control period with those before and after. Therefore, following the method introduced by Cermak and Knutti (2009), a feed-forward neural network was used to establish a statistical relationship between VOC mixing ratios and meteorological parameters from the reference data (i.e., before the full control) and then to predict the concentrations given the meteorological conditions during the games, if there were no restriction measures taken. Thus, the difference between the observed and predicted VOC concentrations is helpful to determine the effective changes due to the air quality measures.

The multilayer perceptron (MLP) network in SPSS17.0 was used in this work. As the concentrations of VOCs displayed near lognormal distributions, the natural logarithm of VOC concentration, $\ln (\mathrm{VOC})$, was selected as the "dependent variable" of inputs in the MLP network, and the meteorological parameters as "covariates" of inputs, including wind vector $(u, v$, previous day $u$, previous day $v)$, precipitation, relative humidity, temperature and pressure. The observed data from 3 July to 20 July (before the full control) were used as the reference data $(n=1611)$ to set up a relationship between $\ln (\mathrm{VOC})$ and meteorological parameters. Of the reference data $70 \%$ was chosen randomly as training sample to train the neural network, $20 \%$ of the data as testing sample used to track errors during training in order to prevent overtraining, and the rest of the data (10\%) as the holdout sample used to assess the final neural network for validation. The network contained one hidden layer, sigmoid functions were chosen as the activation functions for hidden layer and output layer. Given that there was no statistical difference between the prediction and the corresponding observation for validation data, the same approach was used for predicting the concentrations of VOCs from 21 July to 27 August.

\subsection{Model description for OVOC simulation}

A zero-dimensional box model, which is similar to the one used by $\mathrm{Lu}$ et al. (2012) and $\mathrm{Li}$ et al. (2014), was employed in this work to examine the change of OVOC production under the influence of emission restrictions. The box model uses a subset of the MCM3.2 (available online at http://mcm.leeds.ac.uk/MCM) which contains fully explicit chemical mechanisms for 57 kinds of VOCs (including 7 oxygenated hydrocarbons) plus $\mathrm{CH}_{4}$ and $\mathrm{CO}$. The model calculations were constrained by measured $\mathrm{C}_{2}-\mathrm{C}_{11}$ NMHCs, 
$\mathrm{CO}, \mathrm{CH}_{4}, \mathrm{O}_{3}, \mathrm{NO}, \mathrm{NO}_{2}, \mathrm{HONO}$, and physical parameters (i.e., photolysis frequencies, water vapor concentration, temperature, and pressure). The time step of the model calculation was set to $30 \mathrm{~min}$. Here, 57 VOCs were measured by online GC-MS/FID and PTR-MS including $20 \mathrm{C}_{2}-\mathrm{C}_{11}$ alkanes, $11 \mathrm{C}_{2}-\mathrm{C}_{5}$ alkenes, 15 aromatics, acetylene, isoprene, pinenes, formaldehyde, acetaldehyde, methanol, acetone, MEK and MVK + MACR. The $\mathrm{CH}_{4}$ concentration was assumed to be $2.5 \mathrm{ppm}$, taken from previous observations in Beijing ( $\mathrm{Su}, 2003)$. The photolysis rates for $\mathrm{O}^{1} \mathrm{D}$ and $\mathrm{NO}_{2}$ were constrained with the measured values at the site. The photolysis rates for HONO, aldehydes and ketones were calculated by the model for clear sky conditions (Saunders et al., 2003) and then scaled by the measured $J\left(\mathrm{NO}_{2}\right)$. Dry deposition rate for all modeled species was set to $1.2 \mathrm{~cm} \mathrm{~s}^{-1}$ by assuming a well-mixed boundary layer with a height of $1000 \mathrm{~m}$, corresponding to a lifetime $\left(\tau_{\mathrm{D}}\right)$ of $24 \mathrm{~h}$. Several additional model scenarios (listed in Table 3 ) were constructed to test the sensitivity of simulated OVOC concentrations with assumed deposition rates and boundary layer evolution. The model was operated for the full control period (26 July-27 August) with 2 days spin-up time to reach steady state. The relative changes of the model results responding to the controlled emissions were compared with the observed changes of OVOCs before and during the full control (Sect. 4).

The model uncertainty is mainly caused by the uncertainty of all input parameters (VOCs, trace gas, meteorological parameters, etc.) and reaction rates used in the model. Here, the total uncertainty was estimated by the error propagation from the errors of all considered parameters, as described in Li et al. (2014). The modeled concentrations of OVOCs in the base model had an uncertainty of $40-50 \%$.

\section{Results and discussion based on observations}

\subsection{Diurnal variations of VOCs before and during the control}

Table 1 summarizes the averaged meteorological parameters before (3-20 July) and during the full control period (21 July-27 August). Meteorological conditions in the two time periods were similar, except that the average ambient $T$ and UVA before the control were slightly higher than respective values during the full control, which would affect the emission of biogenic VOCs (dominated by isoprene). As an overview of the changes in VOC concentrations between the two periods, the $10 \mathrm{~min}$-average diurnal variations of the mixing ratios of 12 VOC species were compared in Fig. 1. Aromatics, as a group of primary anthropogenic NMHCs, mainly come from vehicle exhaust and solvent usage in Beijing (Liu et al., 2005; Yuan et al., 2010b). They dropped to the minimum at 14:00-15:00 for both of the two time periods (Fig. 1a-f). Compared to the period prior to 20 July, an obvious decrease (50-60\%) in aromatics occurred after 21 July, especially at rush hours, which may be caused by the traffic restrictions. Oxygenated species at the PKU site, from both secondary photochemical production and primary emissions, reached high concentrations at noon and in the late evening (Fig. 1h-1). Some differences of ketones and aldehydes between the two time periods were found, but not as prominent as aromatics. It is difficult to assess the effect of control measures on OVOC species merely based on the changes in their absolute concentrations before and during the control. In the following section a neural network analysis is used to subtract meteorological effects and quantify the influence of emission reductions on ambient levels of NMHCs and OVOCs.

\subsection{Effect of emission control measures on mixing ratios of VOCs}

Assuming that no emission restrictions had been in place from 21 July to 27 August, the "uncontrolled" VOCs corresponding to the meteorological conditions encountered at that time were predicted by the MLP network using the relationship between VOCs and meteorological parameters from the reference data (before 21 July). Figures 2 and 3 present the probability distributions of the observed (red) and predicted (blue) $\ln (\mathrm{VOC})$ before and during the control period for NMHCs and OVOCs, respectively. For most aromatics, the observation and prediction values from the uncontrolled period matched well with each other, but the observed data from the controlled period clearly shifted towards lower values compared to the prediction. This suggests that the influence of the traffic restriction on aromatics was effective. Acetonitrile $\left(\mathrm{CH}_{3} \mathrm{CN}\right)$, unlike other NMHCs, did not show any difference between the observed and predicted values for both the controlled and uncontrolled periods. As acetonitrile is usually considered as a tracer for biomass burning and is seldom detected in automobile emissions (Wang et al., 2007), its concentration should be hardly affected by the traffic control. The measured median value of acetonitrile before 21 July was slightly higher than that after 21 July. This discrepancy $(15 \%)$ in the absolute concentrations between the two time periods could be explained by the changes in meteorological conditions or pollution transport. The reductions of most OVOCs were also observed relative to what was to be expected without emission controls, although the deviations in OVOCs were not as notable as aromatics (Fig. 3).

The predicted and observed results of NMHCs and OVOCs in the controlled period are compared in Table 2, and the results for the uncontrolled period are listed in Table $\mathrm{S} 1$. The median concentrations of aromatics dropped by 32-47\% compared to the levels expected under the same meteorological conditions without traffic controls. The median values of formaldehyde, acetaldehyde, MEK and methanol were decreased by $12.9,15.8,17.1$ and $19.6 \%$, respectively. Isoprene, unlike aromatics, exhibited a broad peak from the early morning to the afternoon (Fig. 1g), which followed the 
Table 1. Summary of meteorological parameters at the PKU site before and during the full control (average $\pm 1 \sigma$ SD).

\begin{tabular}{lllllccc}
\hline Time period & $T$ & $\left({ }^{\circ}\right)$ & $\mathrm{RH}$ & $(\%)$ & Precipitation $(\mathrm{mm})$ & $\mathrm{WS}_{\left(\mathrm{m} \mathrm{s}^{-1}\right)}$ & $\left.\mathrm{UVA}_{(\mathrm{W} \mathrm{m}}^{-2}\right)$ \\
\hline Before the full control & 3-20 July & $28.9 \pm 4.5$ & $66.9 \pm 20.0$ & $0.04 \pm 0.37$ & $1.1 \pm 0.9$ & $6.6 \pm 8.7$ \\
During the full control & 21 July-27 August & $28.0 \pm 4.1$ & $67.9 \pm 17.5$ & $0.05 \pm 0.51$ & $0.9 \pm 0.8$ & $5.3 \pm 7.1$ \\
\hline
\end{tabular}
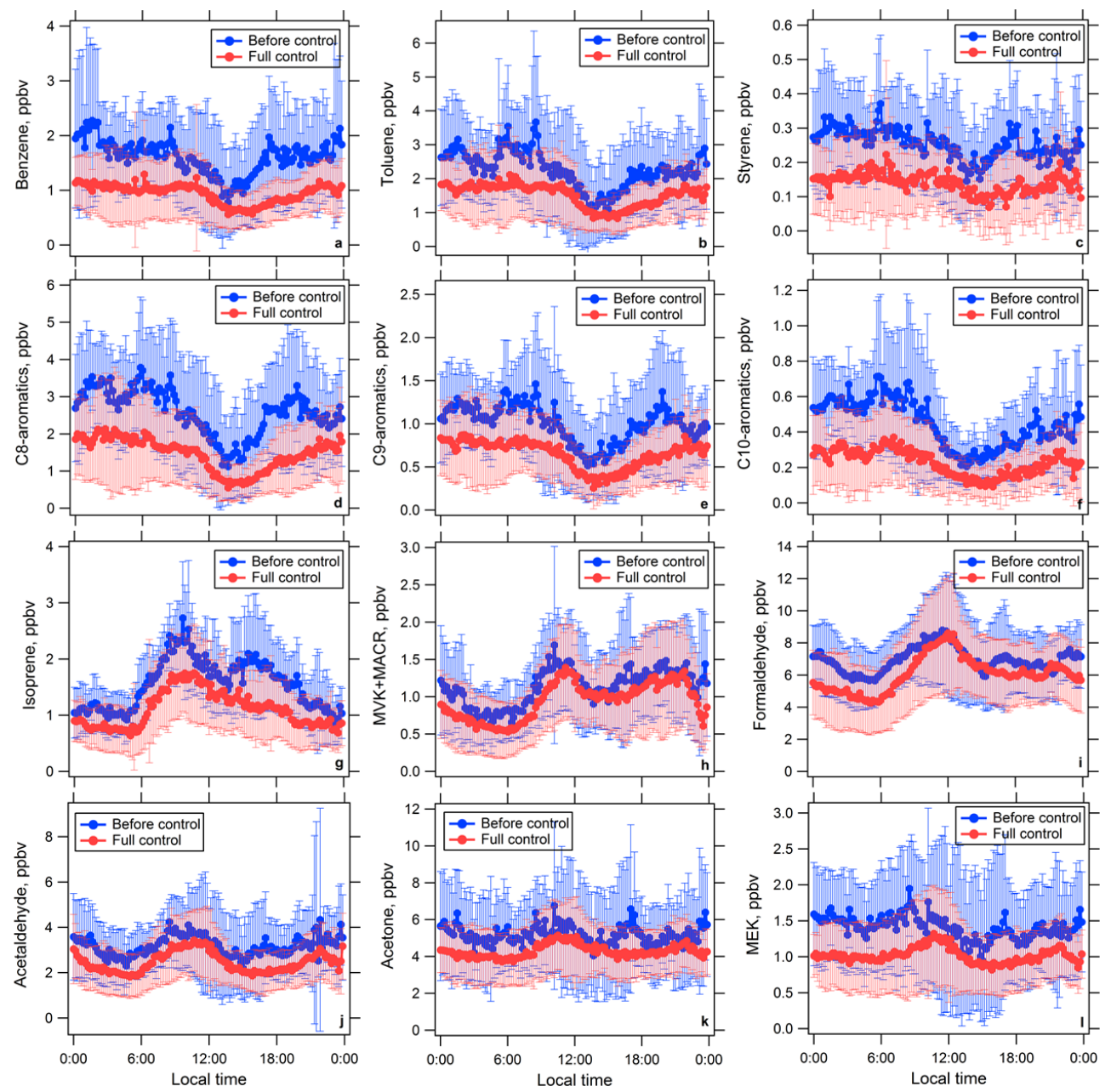

Figure 1. The $10 \mathrm{~min}$ average diurnal variations of several NMHCs and OVOCs measured by PTR-MS at the PKU site before (1-20 July, blue) and during the full control (21 July-27 August, red), respectively. (a) benzene, (b) toluene, (c) styrene, (d) C8 aromatics, (e) C9 aromatics, (f) $\mathrm{C} 10$ aromatics, (g) isoprene, (h) MVK + MACR, (i) formaldehyde, (j) acetaldehyde, (k) acetone, (l) MEK. The error bars represent standard deviations (SDs) for those compounds before (blue) and during the full control (red).

solar radiation and temperature cycles and showed the characteristics of local biogenic emissions in the daytime. In addition, their low concentrations at night likely indicate small local emissions from vehicles near the site. Compared to the values before the control isoprene and MVK + MACR were estimated to be reduced by 26 and $11 \%$ from 21 July to 27 August, respectively, which was caused by a combined effect of the lower temperature, solar radiation and the control measures.
The relative difference between predicted and measured acetone was as small as $1 \%$, implying that the emission controls had little or no effect on acetone. The unchanged acetone levels were probably influenced by its high regional background, which was around 1.7-2 ppb at the PKU site accounting for $43-47 \%$ of acetone concentration (Liu et al., 2009; Yuan et al., 2012). The acetone background was closely related to transport of photochemical plumes from the surrounding areas (such as Hebei Province and Tianjin) to Beijing. As the emission reductions were implemented 
Table 2. Comparison of the observed and predicted values of median $\ln$ (VOC) and their corresponding concentrations during the full control period, and the deviations between observed and predicted concentrations, together with the outputs $\mathrm{P}(t)$ from Student's $t$ test for the two data sets, where $\mathrm{P}(t)<0.05$ implies that the difference in the two data sets is statistically significant at the confidence level of $95 \%$.

\begin{tabular}{lrrrrrrr}
\hline & \multicolumn{2}{c}{ Median ln(VOC) } & & Concentration (ppbv) & \multicolumn{2}{c}{$\begin{array}{c}\text { Deviation of } \\
\text { concentrations }\end{array}$} \\
& observation & prediction & $\mathrm{P}(t)$ & observation & prediction & $(\%)$ & $R$ \\
\hline Benzene & -0.23 & 0.25 & 0.00 & 0.79 & 1.28 & -38.2 & 0.48 \\
Toluene & 0.24 & 0.63 & 0.00 & 1.27 & 1.88 & -32.5 & 0.41 \\
C8 aromatics & 0.12 & 0.73 & 0.00 & 1.12 & 2.08 & -46.0 & 0.44 \\
C9 aromatics & -0.63 & -0.17 & 0.00 & 0.53 & 0.84 & -37.0 & 0.26 \\
C10 aromatics & -1.70 & -1.05 & 0.00 & 0.18 & 0.35 & -47.5 & 0.32 \\
Styrene & -2.11 & -1.66 & 0.00 & 0.12 & 0.19 & -36.5 & 0.22 \\
Acetonitrile & -1.45 & -1.46 & 0.72 & 0.23 & 0.23 & 0.4 & 0.36 \\
HCHO & 1.72 & 1.85 & 0.00 & 5.56 & 6.38 & -12.9 & 0.45 \\
Acetaldehyde & 0.78 & 0.95 & 0.00 & 2.18 & 2.59 & -15.8 & 0.52 \\
Acetone & 1.39 & 1.40 & 0.36 & 4.02 & 4.06 & -1.0 & 0.36 \\
MEK & -0.11 & 0.08 & 0.00 & 0.90 & 1.08 & -17.0 & 0.64 \\
Methanol & 1.95 & 2.17 & 0.00 & 7.06 & 8.78 & -19.6 & 0.31 \\
Isoprene & -0.07 & 0.24 & 0.00 & 0.94 & 1.27 & -26.6 & 0.55 \\
MVK+ MACR & -0.27 & -0.15 & 0.00 & 0.76 & 0.86 & -11.3 & 0.72 \\
\hline
\end{tabular}

within the Beijing area, i.e., in a range of about $150 \mathrm{~km}$ radius, the regional background of acetone should hardly be affected by the emission controls. So, it seems to be difficult to reduce the level of acetone in Beijing if relying solely on the control of local emissions.

With the exception of acetonitrile and acetone, the deviation for all other species between the full control period and the uncontrolled days is statistically significant from Student's $t$ test at the $95 \%$ level $(\mathrm{P}(t)<0.05)$. By contrast, the reference data from the uncontrolled period were well predicted by the MLP simulations (as shown in Fig. S3), with correlation coefficients ranging from 0.79 to 0.94 and successful $t$ tests for all the species (presented in Table S1). Thus, the emission restrictions implemented in Beijing had significant effects on the NMHCs dominated by vehicular emissions, which is consistent with those results in Wang et al. (2010a). The reductions in OVOC species are moderate in comparison to their precursors (e.g., NMHCs), which are subject to the combined influence of controlled direct emissions, local production from reduced precursors and regional formation processes (transport). In subsequent model analyses (Sect. 4), the changes of OVOCs produced from local NMHC oxidation will be discussed.

\subsection{Emission ratios for anthropogenic NMHCs}

As NMHCs play significant roles on the formation of secondary OVOCs, emission ratios (ERs) of NMHCs before and during the full control were compared in this section to determine whether the emission restrictions also altered the relative emission of OVOC precursors (i.e., source pattern of NMHCs), in addition to reducing their total emission amounts. According to previous studies on NMHC source apportionment in Beijing (Liu et al., 2005; Song et al., 2007; Lu et al., 2007; Wang et al., 2010a), vehicle exhaust is the largest contributor to ambient NMHCs with $40-58 \%$, followed by solvent usage and painting processes (18-30\%), gasoline evaporation (7-13\%) and chemical plants (3-15\%).

The emission ratio for VOCs is defined as the ratio of VOC species relative to a reference compound in fresh emissions without undergoing photochemical processes. It can be determined using a photochemical-age-based method presented in de Gouw et al. (2005), Warneke et al. (2007) and Borbon et al. (2013). The degradation of NMHCs by their reactions with $\mathrm{OH}$ is described as Eq. (1), where $\mathrm{ER}_{\mathrm{NMHC}}$ represents the emission ratio of NMHC species relative to $\mathrm{CO}$, and $k_{\mathrm{NMHC}}$ and $k_{\mathrm{CO}}$ are the $\mathrm{OH}$ rate coefficients for NMHC and CO, respectively. The ERs reflect the comprehensive effect of all emission sources on ambient NMHCs at the site. Here, the photochemical age of the sampled air masses was calculated by the measured ratio of toluene/ benzene (T/B) using Eq. (2), and the initial T/B was set to $2.8 \pm 0.7$. The $24 \mathrm{~h}$ averaged concentration of $\mathrm{OH}$ was taken as $2.5 \times 10^{6}$ molecules $\mathrm{cm}^{-3}$ which comes from $\mathrm{OH}$ measurements at a suburban site near Beijing during the CAREBEIJING 2006 campaign (Lu et al., 2013). The ratio of NMHCs (e.g., toluene, $m, p$-xylene) to CO decreases with the photochemical age (Fig. 4). The yellow line in Fig. 4a is the linear fit between $\ln ([$ toluene]/[CO]) and the photochemical age. The emission ratio of toluene relative to $\mathrm{CO}$ $\left(E_{\text {toluene }}\right)$ is determined by the intercept of the linear fit. It is noted that a constant $\mathrm{CO}$ background of $120 \mathrm{ppbv}$ was subtracted from measured $\mathrm{CO}$ when plotting $\mathrm{VOC} / \mathrm{CO}$ versus photohemical age, the $\mathrm{CO}$ background was determined from the minimum concentrations when prevailing winds 

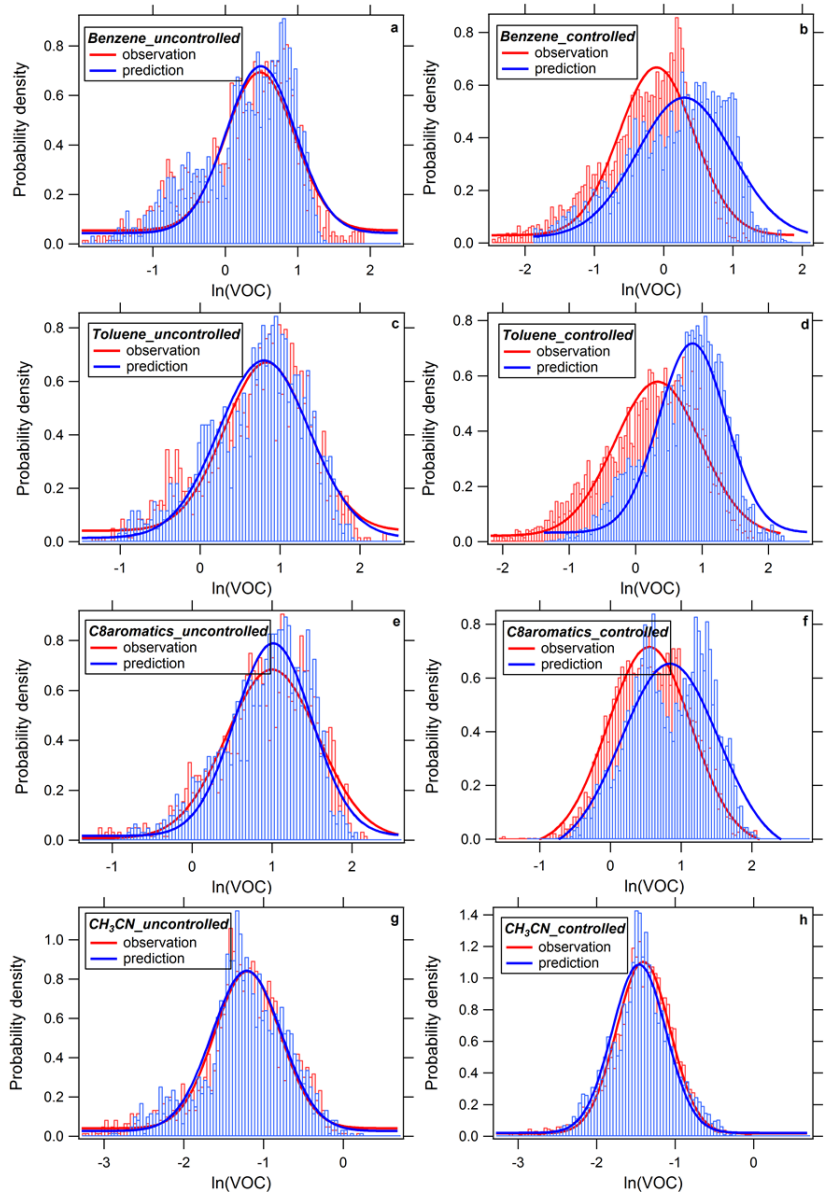

Figure 2. Probability density distribution of the observed $\ln (\mathrm{VOC})$ (red) and the predicted values (blue) before the full control (left column) and after the full control (right column) for NMHC species: $(\mathbf{a}, \mathbf{b})$ benzene, $(\mathbf{c}, \mathbf{d})$ toluene, $(\mathbf{e}, \mathbf{f}) \mathrm{C} 8$ aromatics, and $(\mathbf{g}, \mathbf{h})$ acetonitrile.

were from the northeast and relatively clean air was measured.

$$
\begin{aligned}
& \frac{[\mathrm{NMHC}]}{[\mathrm{CO}]}=\frac{[\mathrm{NMHC}]}{\Delta \mathrm{CO}}=\mathrm{ER}_{\mathrm{NMHC}} \\
& \times \exp \left[-\left(k_{\mathrm{NMHC}}-k_{\mathrm{CO}}\right)[\mathrm{OH}] \Delta t\right] \\
& \Delta t=\frac{1}{[\mathrm{OH}]\left(k_{\text {toluene }}-k_{\text {benzene }}\right)} \times\left[\ln \left(\left.\frac{\text { [toluene }]}{\text { [benzene }]}\right|_{t=0}\right)\right. \\
& \left.-\ln \left(\left.\frac{[\text { toluene }]}{[\text { benzene }]}\right|_{t=t}\right)\right]
\end{aligned}
$$

As discussed in Warneke et al. (2007), the error of emission ratio arises from the uncertainty of measured benzene and toluene and the estimation of the initial T/B ratio in Eq. (2). The total ER error was then calculated conservatively by linear addition of the above two errors. The measurement uncertainty of benzene and toluene by PTR-MS or GC-MS is about $10-15 \%$. As initial T/B ratio from the same source category varies with different operating conditions, the error
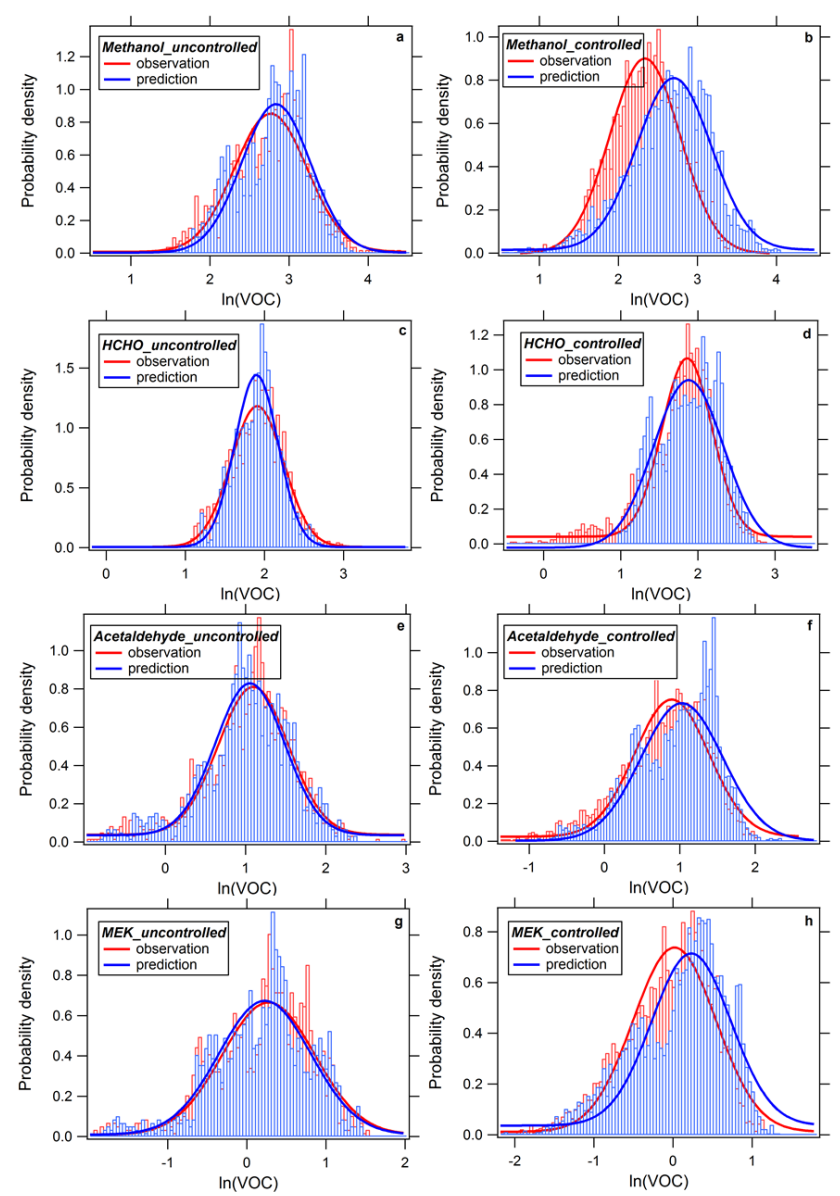

Figure 3. Probability density distribution of the observed $\ln (\mathrm{VOC})$ (red) and the predicted values (blue) before the full control (left column) and after the full control (right column) for OVOC species: (a, b) methanol, (c, d) HCHO, (e, f) acetaldehyde, and (g, h) MEK.

from selecting initial ratios can be regarded as the uncertainty of source profiles, which is usually in the range of 15-20\%. So, the total uncertainty of ER estimation is around $30-35 \%$.

Since the GC-MS/FID data was only available for the full control period of 2008, VOC data measured at the PKU site in August 2005 (Liu et al., 2009) were used as a reference for uncontrolled situations. The emission ratios for all measured hydrocarbons versus CO in Beijing for August 2008 and August 2005 are compared in Fig. 5, and the values are tabulated in Table S2 together with some ER results from two US cities in previous work (Warneke et al., 2007; Borbon et al., 2013). In general, the ERs for all groups of NMHCs in the 2 years agree with each other within a factor of 1.5 (indicated by the shaded area in Fig. 5). For traffic-related NMHCs including most alkenes, acetylene, benzene, toluene and ethylbenzene, the difference of the ERs between 2005 and 2008 ranged from \pm 6.5 to $\pm 29 \%$, within the range of combined error (30\%) for ER calculations. This suggests that the pollution control measures did not significantly change the emission composition of the species closely related to vehicu- 


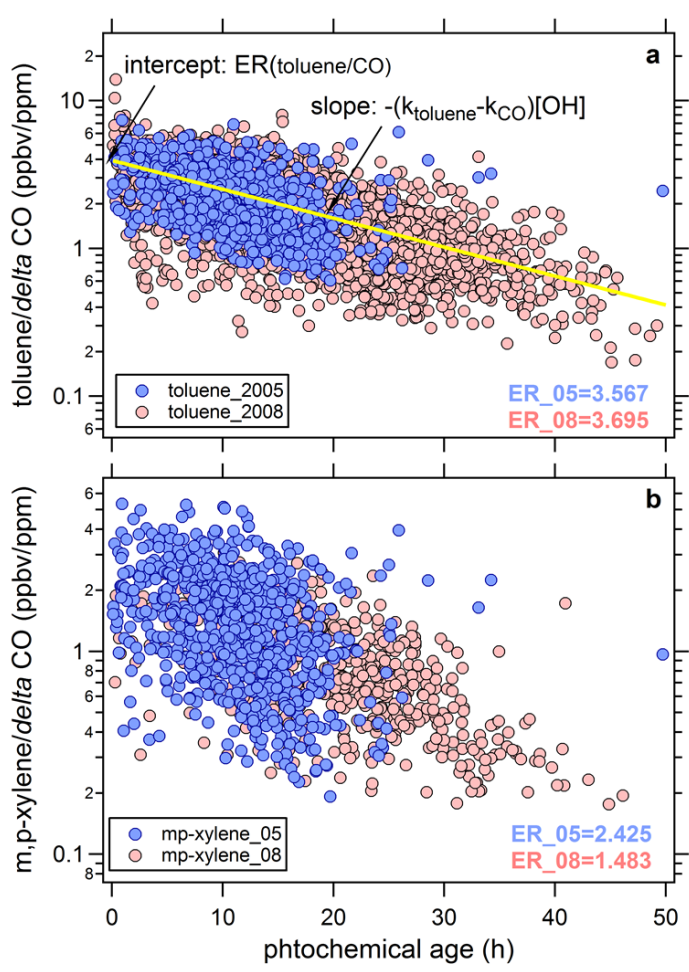

Figure 4. The ratios of toluene/CO (a) and m,p-xylene/CO (b) vs. the photochemical age of the sampled air mass in Beijing for August 2008 (pink) and August 2005 (blue).

lar emissions, although the absolute concentrations of those species did drop by half (e.g., toluene/CO in Fig. 4a). A recent work by Wang et al. (2014) also reported a good agreement of emission ratios for most NMHCs at the PKU site in the summertime of 2008, 2010 and 2011. These results reflect the similarity of NMHC compositions for typical urban emissions of Beijing.

Some alkanes (ethane, $n$-butane, $i$-butane, $n$-pentane) and aromatics ( $m, p$-xylene and $o$-xylene, labeled in Fig. 5) showed a larger variability (35-50\%) in the two ER data sets for 2005 and 2008. For example, the emission ratio for $m, p$ xylene in August 2008 was observed to be $38 \%$ lower than the value in August 2005, shown in Fig. 4b. Besides an additional error (5-10\%) from subtracting a constant CO background in ER estimation, one possible reason for this larger difference is that the abovementioned species also come from "other" emission sources in addition to vehicles. $\mathrm{C}_{8}$ aromatics were observed as the main components from solvent usage in Beijing (Yuan et al., 2010b). The 2008 control measures included temporary closures of chemical plants, painting processes and constructions involving evaporation emissions. If the influence of the control measures on emissions of solvent usage and of automobile source occurred to different degrees, the averaged emission profiles of the city would be changed for the characteristic species (i.e., xylenes) of solvent usage.

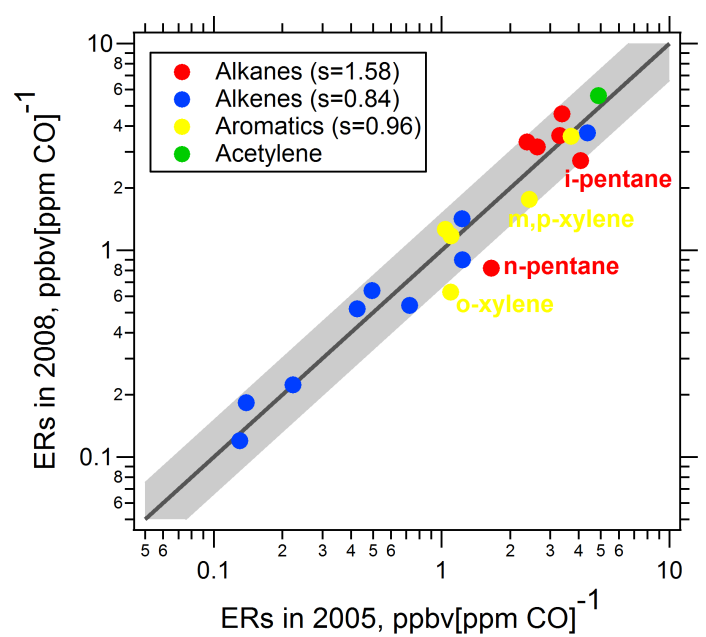

Figure 5. Comparison of the emission ratios (ERs) of NMHCs relative to $\mathrm{CO}$ in the 2008 and 2005 summers at the PKU site, where each point represents one compound and different colors indicate the classes of NMHCs. The black line represents the $1: 1$ line and the shaded area shows the agreements within a factor of 1.5.

The ERs of hydrocarbons related to vehicle emissions (acetylene, ethylene, propene, benzene and toluene) in Beijing generally agree with those in two US cities (in Table S2), indicating that emission patterns of automobile sources in different cities showed a similarity. Greater deviations of lighter alkanes, some $\mathrm{C}_{4}$ and $\mathrm{C}_{5}$ alkenes and higher aromatics were found probably because of the unique characteristics of emission sources (e.g., fuel types, vehicle fleet ages, solvent and paint types, industrial procedures, etc.) for each city.

\section{Modeling analysis for the changes of OVOCs}

To better understand the relationship between reduced precursors (NMHCs) and OVOC concentrations during the CAREBEIJING 2008 experiment, a box model using the recent version of MCM was applied in this study. According to the source apportionments of OVOCs in Beijing (Liu et al., 2009; Yuan et al., 2012), 60-70\% of aldehydes are attributed to hydrocarbon oxidation (secondary formation), the contributions from primary sources are more important for ketones $(38-80 \%)$ and alcohols (48-74\%), and the contribution of secondary formation was not detected in methanol. Therefore, the following sections will focus on the formation of aldehydes and ketones. The primary emissions for aldehydes and ketones are not included in the base model but added to subsequent model scenarios for comparison. 
Table 3. Model scenarios performed in OVOC simulations during the CAREBEIJING 2008.

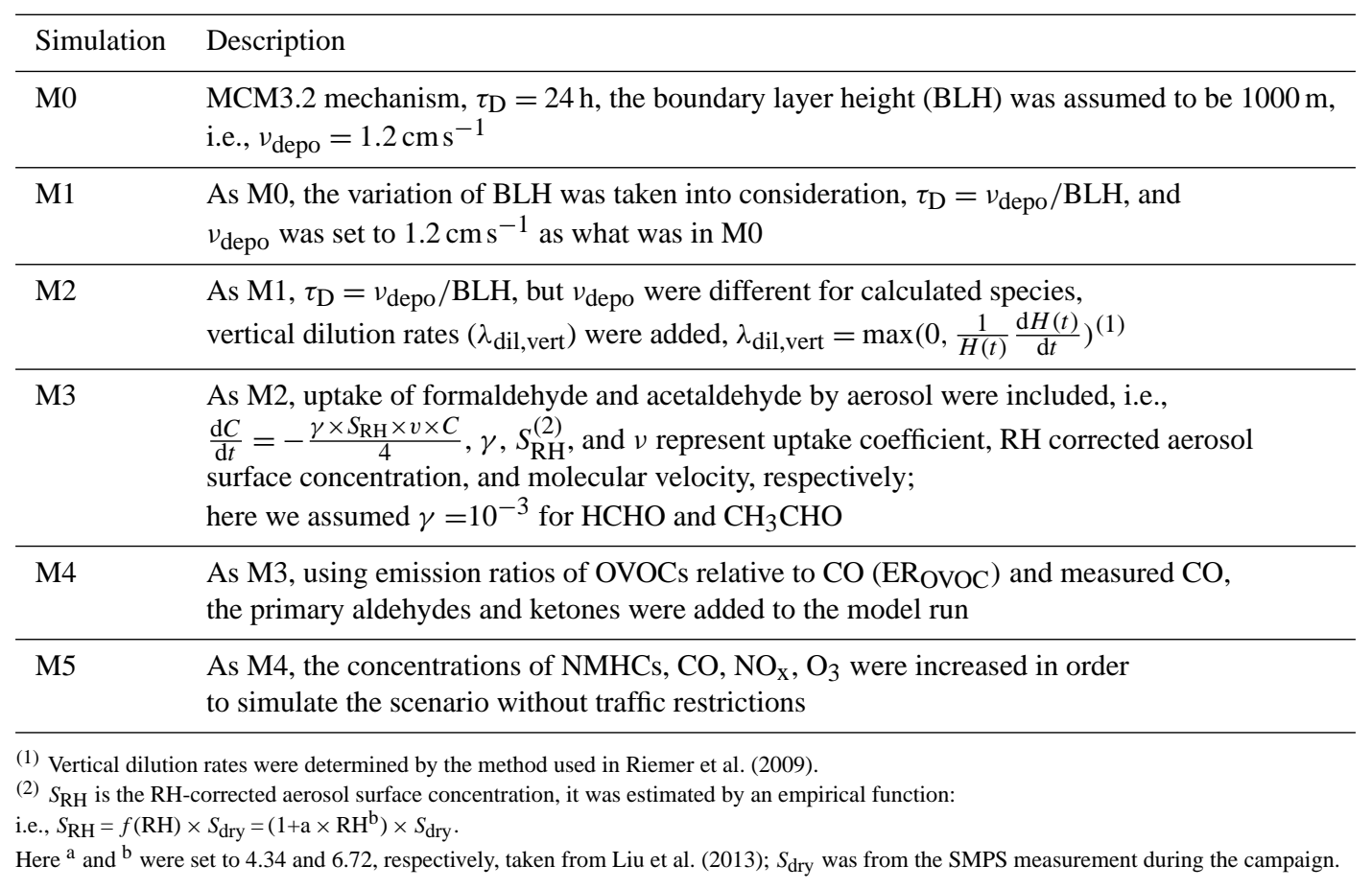

\subsection{Description of model scenarios and $\mathrm{OH}$ simulation results}

Six model scenarios for OVOC simulations are summarized in Table 3. M0 is the base case model with the settings described in Sect. 2.3. In M1, the variation of the boundary layer height (BLH) at a suburban site near Beijing taken from Liu et al. (2011) was included in the model run. The dry deposition rate in $\mathrm{M} 1$ was set to $1.2 \mathrm{~cm} \mathrm{~s}^{-1}$, as used in the model scenario M0. In M2, different dry deposition rates were applied to the simulated species. The values were taken from Emmerson et al. (2007) for $\mathrm{HNO}_{3}\left(2 \mathrm{~cm} \mathrm{~s}^{-1}\right)$, organic peroxides $\left(0.5 \mathrm{~cm} \mathrm{~s}^{-1}\right), \mathrm{H}_{2} \mathrm{O}_{2}$ and organic nitrates $\left(1.1 \mathrm{~cm} \mathrm{~s}^{-1}\right)$, from Li et al. (2014) for HCHO and other aldehydes $\left(1 \mathrm{~cm} \mathrm{~s}^{-1}\right)$. In addition, the vertical dilution rates that represent entrainment of a growing boundary layer were introduced to all modeled species in M2. These are estimated from the growth rate of boundary layer heights (Riemer et al., 2009), described by the equation given in Table 3. In M3, the loss of two aldehydes on particle surface was estimated by using the uptake coefficient of $10^{-3}$ form the literature (Jayne et al., 1996; Li et al., 2011); the equation (Jayne et al., 1996) for calculating uptake rate is shown in Table 3. In M4, the primary sources for formaldehyde, acetaldehyde, acetone and MEK were included by employing the emission ratios of OVOCs relative to $\mathrm{CO}$ and measured $\mathrm{CO}$ concentration.

$\mathrm{OH}$ concentrations were not directly measured in August 2008. As strong relations between observed $\mathrm{OH}$ and ozone photolysis frequency $\left(J\left(\mathrm{O}^{1} \mathrm{D}\right)\right)$ were found in field stud- ies (Rohrer et al., 2014; Rohrer and Berresheim, 2006), it makes sense to estimate $\mathrm{OH}$ radicals using the empirical $\mathrm{OH}-$ $J\left(\mathrm{O}^{1} \mathrm{D}\right)$ relations when lacking direct measurements of $\mathrm{OH}$. Here, the modeled $\mathrm{OH}$ by the box model was compared with the calculated $\mathrm{OH}$ by an observed dependence of $\mathrm{OH}$ on $J\left(\mathrm{O}^{1} \mathrm{D}\right)$ that was obtained from $\mathrm{OH}$ measurements in CAREBEIJING 2006 (Lu et al., 2013). Figure 6a shows the average diurnal profiles of modeled and calculated $\mathrm{OH}$, indicating that the modeled $\mathrm{OH}$ in the daytime shows a broader peak and it was overestimated by $\sim 22 \%$ compared to the calculations from the empirical relation. Relatively higher nighttime $\mathrm{OH}$ was determined from the calculation, due to the intercept of the empirical OH- $J\left(\mathrm{D}^{1} \mathrm{D}\right)$ function. This intercept includes all processes that are light independent (Rohrer and Berresheim, 2006), implying that unknown $\mathrm{OH}$ production probably occurred at night (Lu et al., 2014). As the uncertainties of $\mathrm{OH}$ measurement and $J\left(\mathrm{O}^{1} \mathrm{D}\right)$ measurement are 20 and $10 \%$, respectively, from Lu et al. (2013), in addition to a fitting error between $\mathrm{OH}$ and $J\left(\mathrm{O}^{1} \mathrm{D}\right)$, the difference between the modeled and calculated $\mathrm{OH}$ is acceptable. This hints that the box model employed here provides a reasonable explanation of radical chemistry in the urban environments.

\subsection{OVOCs simulation}

\subsection{1 $\mathrm{HCHO}$ and $\mathrm{CH}_{3} \mathrm{CHO}$}

Unlike $\mathrm{OH}$, a large difference with a factor of 2-4 was found between the measured and modeled concentrations of aldehydes by the base model (M0), as summarized in Table S3. 

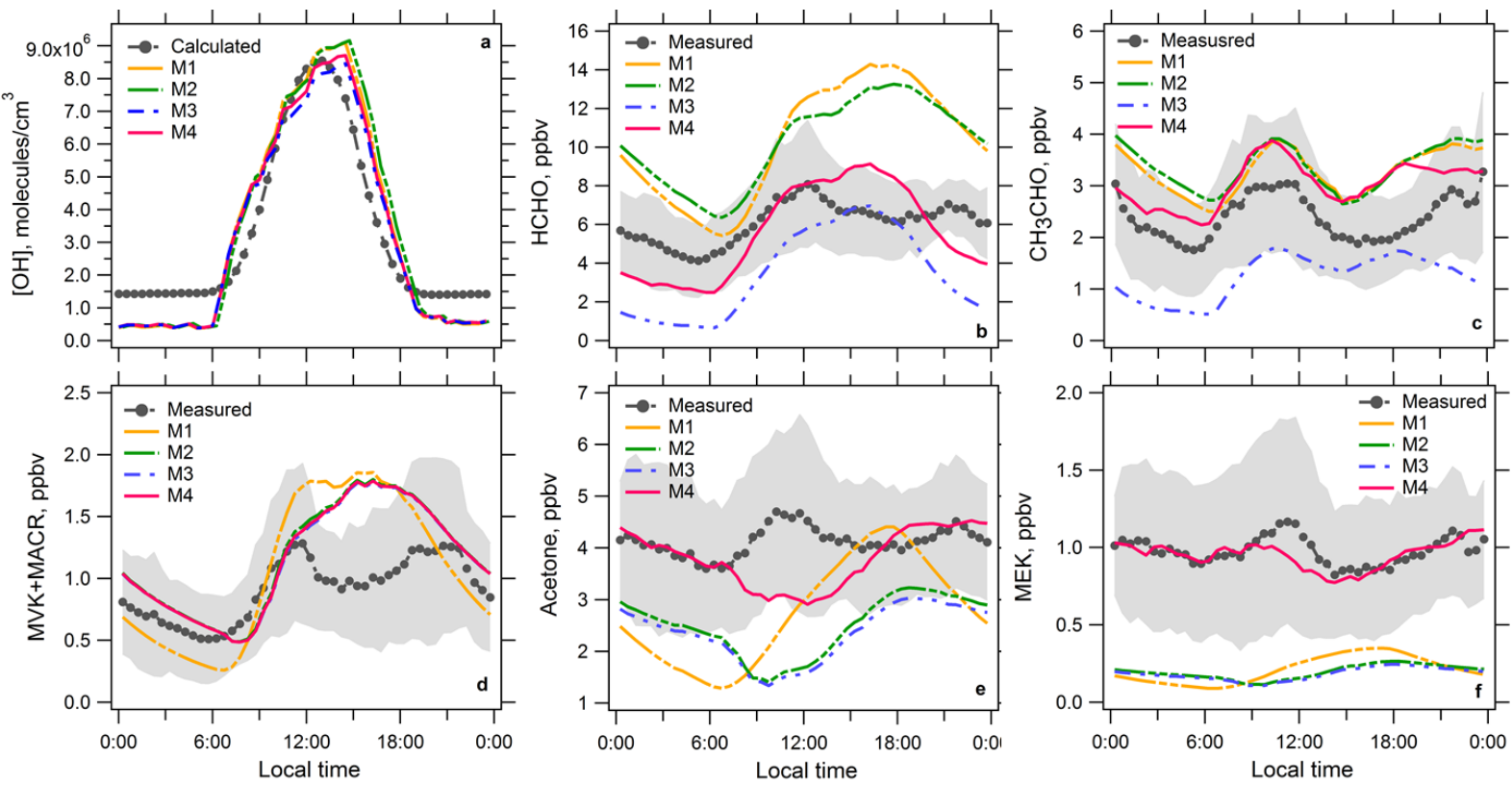

Figure 6. The $30 \mathrm{~min}$ average modeled and measured (or calculated) concentrations of (a) $\mathrm{OH}$ radical, (b) HCHO, (c) acetaldehyde, (d) MVK + MACR, (e) acetone and (f) MEK plotted as diurnal patterns from 26 July to 27 August. The dashed black lines with solid dots indicate measured (or calculated) data, grey areas show one standard deviation from the averaged values. The dash-dotted yellow lines, dashed green lines, dash-dotted blue lines and solid magenta lines represent the modeled concentrations by simulations M1, M2, M3 and M4, respectively.

After modifying deposition rates or/and vertical dilution, the averaged concentrations of $\mathrm{HCHO}$ and acetaldehyde in $\mathrm{M} 1$ and $\mathrm{M} 2$ were reduced by 30-37\% compared to the base case. But the modeled concentrations of the two aldehydes are still higher (> 1.5 times) than the measured values. The considerations of BLH variation, different deposition and vertical dilution can help to explain $40-50 \%$ of the large discrepancy between M0 and observations. These results are consistent with a recent study on modeling of formaldehyde and glyoxal in the Pearl River Delta (PRD) (Li et al., 2014).

$\mathrm{Li}$ et al. (2014) estimated that the uptake of formaldehyde and glyoxal by aerosols had the largest contribution $(\sim 50 \%)$ to aldehyde sinks in the presence of acidic aerosols. The $\mathrm{H}_{\mathrm{aer}}^{+}$ presented in the particle phase was calculated from inorganic ions $\left(\mathrm{NH}_{4}^{+}, \mathrm{SO}_{4}^{2-}, \mathrm{NO}_{3}^{-}\right.$and $\left.\mathrm{Cl}^{-}\right)$by HR-TOF-AMS using the method in Zhang et al. (2007). For most days of campaign the average acidity of aerosols was close to neutral due to high ammonia in Beijing. However, for several days (such as 31 July, 1, 4, 11 and 14 August) the averaged $H_{\text {aer }}^{+}$in the daytime was up to $0.01448 \mathrm{~mol} \mathrm{~L}^{-1}$, corresponding to a $\mathrm{pH}$ value of 1.84 , which indicates high aerosol acidity occasionally occurred during the campaign. Jayne et al. (1996) reported a large uptake of formaldehyde by aqueous surface at low temperature and high aerosol acidity. Some lab experiments ( $\mathrm{Li}$ et al., 2011) and field studies also showed loss of $\mathrm{HCHO}$ on aerosols is possible and driven by the liquid water content of the aerosol phase (Toda et al., 2014). In this study, the loss of aldehydes on aerosols through heterogeneous up- take processes was included in M3 and M4 by using the uptake coefficient of $10^{-3}$ for two aldehydes. On average, the modeled $\mathrm{HCHO}$ and $\mathrm{CH}_{3} \mathrm{CHO}$ by $\mathrm{M} 3$ were decreased by 64 and $58 \%$, respectively, compared to M2. Therefore, the loss of aldehydes on aerosol particles might be important in the polluted areas with high production rates of aerosols. Further research on sinks of aldehydes, particularly for heterogeneous uptake processes, is still needed in future studies.

The model scenarios M0-M3 only estimated photochemical production of OVOCs (secondary OVOCs) and did not include their primary emissions from sources. As OVOC source apportionment showed that Beijing is characterized by high anthropogenic emissions of OVOCs (primary OVOCs) (Yuan et al., 2012; Chen et al., 2014), primary aldehydes were added to model simulation M4 by using the ERs of OVOCs relative to $\mathrm{CO}(\mathrm{HCHO} / \mathrm{CO}=2.74$, $\mathrm{CH}_{3} \mathrm{CHO} / \mathrm{CO}=2.82$ ) and measured $\mathrm{CO}$. The ERs of OVOCs were calculated from the multivariate regression results for OVOC data at the PKU site in Yuan et al. (2012). Compared with $\mathrm{M} 0-\mathrm{M} 3$, the average of modeled $\mathrm{HCHO}$ and $\mathrm{CH}_{3} \mathrm{CHO}$ by $\mathrm{M} 4$ show a better agreement with the observations. As shown in Fig. $6 \mathrm{~b}$ and c, the maximum of modeled $\mathrm{HCHO}$ in M4 occurred at 15:00-16:00 LT, which was delayed by about $3 \mathrm{~h}$ from the observations. The diurnal pattern of simulated acetaldehyde was well matched with the observed variation most of the time. The calculated primary $\mathrm{HCHO}$ and $\mathrm{CH}_{3} \mathrm{CHO}$ by M4 contributed 41 and $58 \%$ of the total modeled concentrations, respectively, higher than the correspond- 
ing results ( $33 \%$ for $\mathrm{HCHO}$ and $42 \%$ for $\mathrm{CH}_{3} \mathrm{CHO}$ ) from the PMF model (Chen et al., 2014).

\subsubsection{MACR}

The model overpredicted the overall concentrations of MVK + MACR by $25 \%$ (Table S3). The diurnal cycle of modeled MVK + MACR is similar in shape and magnitude to the measurements for early morning and nighttime, while the model overestimated the midday peak by a factor of 1.5 in the afternoon (Fig. 6d). This suggests that the box model is able to represent nocturnal sinks of MVK + MACR, but cannot fully explain their productions or/and sinks in the daytime. Karl et al. (2010) found that the observed deposition velocities for MVK + MACR in tropical ecosystems were up to $2.4 \mathrm{~cm} \mathrm{~s}^{-1}, 3-4$ times higher than as used in our model runs $\left(0.6-0.8 \mathrm{~cm} \mathrm{~s}^{-1}\right)$. They also reported that the uptake of MVK + MACR by vegetation followed an exponential increase with leaf temperature, and presented a light dependency as well. So, more MVK + MACR possibly deposits on leaves in the afternoon, which gives evidence of the gap between modeled and observed MVK+MACR during that period.

\subsubsection{Acetone and MEK}

The modeled concentrations of MEK in M0 underestimated the measurements by $56 \%$ (given in Table S3), which is probably caused by the absence of direct anthropogenic emissions of MEK in the model. Sommariva et al. (2011) also found the underprediction of ketones using the box model in the ICARTT (International Consortium for Atmospheric Research on Transport and Transformation) campaign. Similar to $\mathrm{HCHO}$ and $\mathrm{CH}_{3} \mathrm{CHO}$, the primary ketones were added in $\mathrm{M} 4$ by using measured $\mathrm{CO}$ and emission ratios of ketones (acetone $/ \mathrm{CO}=2.23$, MEK $/ \mathrm{CO}=1.22$ ). The modeled ketones in M4 were comparable to the measurements, as listed in Table S3. For diurnal variations, the agreement between modeled and measured MEK concentrations is generally good (shown in Fig. 6f). Figure 7 indicates the simulated contributions of primary and secondary sources to MEK at the PKU site. Primary sources dominated the ambient MEK concentration $(\sim 80 \%)$ on a $24 \mathrm{~h}$ basis, and the contribution of secondary MEK increased to $25 \%$ at noon and early afternoon.

The model cannot reproduce the observed variations of acetone. The acetone peak at noon was probably attributed to some temperature-related emissions (e.g., solvent evaporation). As direct emissions of acetone have not always kept pace with $\mathrm{CO}$, the primary acetone derived from the ER expressed by the acetone/ $\mathrm{CO}$ ratio cannot explain it. Besides combustion sources, in urban areas acetone also directly comes from solvent usage and evaporation, particularly in chemical processing procedures. So, it needs to find a slightly reactive or inert species to work as an indicator

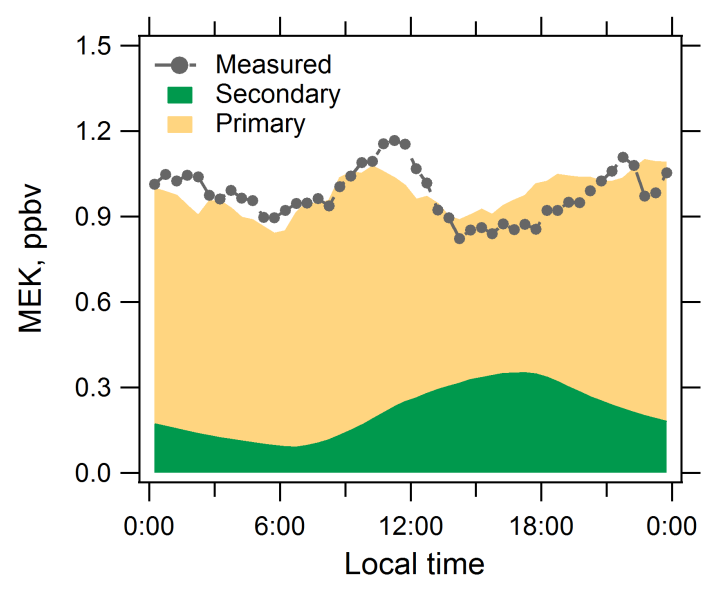

Figure 7. Partitioning of MEK to primary emissions (yellow area) and secondary chemical formation (green area) at the PKU site, and the dashed black lines with solid dots represent measured concentrations.

of non-combustion sources of acetone. $\mathrm{CO}$ and acetylene are frequently used as reference compounds in ERs, while they come mostly from automobile exhaust and fuel combustion, they were seldom observed in solvent usage. Other relatively inert VOCs such as ethane and propane show more variable emission ratios for different sources, so they are also not suitable to be a unique tracer for non-combustion sources. Thus, more detailed measurements on emission characteristics of acetone sources need to be investigated in further studies.

In summary, the box model overestimated the concentrations of aldehydes by a factor of 1.4-1.7 without considering the uptake by aerosols. This discrepancy is mainly attributed to missing sinks, such as vertical dilution, transport and heterogeneous uptake on aerosols. In the presence of fresh emissions, the box model predicted the concentrations and variations of MEK well, but it cannot explain observed acetone and is likely to be affected by unidentified primary emissions or high backgrounds. Despite the existence of drawbacks on estimation of sinks, the box model can still give an overview of the relative importance of different precursors on the production of secondary OVOCs. It can also be used as a tool to quantify the relative changes in OVOC production due to the reduced precursors and other pollutants during the emission control period.

\subsection{Secondary production of OVOCs}

Figure 8a-c illustrate averaged diurnal variations of the production of formaldehyde, acetaldehyde and acetone from different groups of NMHCs in M2 during the full control period. As an average, the photooxidation of alkenes contributed most to secondary HCHO production with a percentage of $54 \%$, followed by the oxidation of isoprene (30\%) and aromatics $(15 \%)$, the contributions of pinenes and alkanes were negligible $(<1 \%)$. The contributions of $\mathrm{C}_{2}-\mathrm{C}_{4}$ 


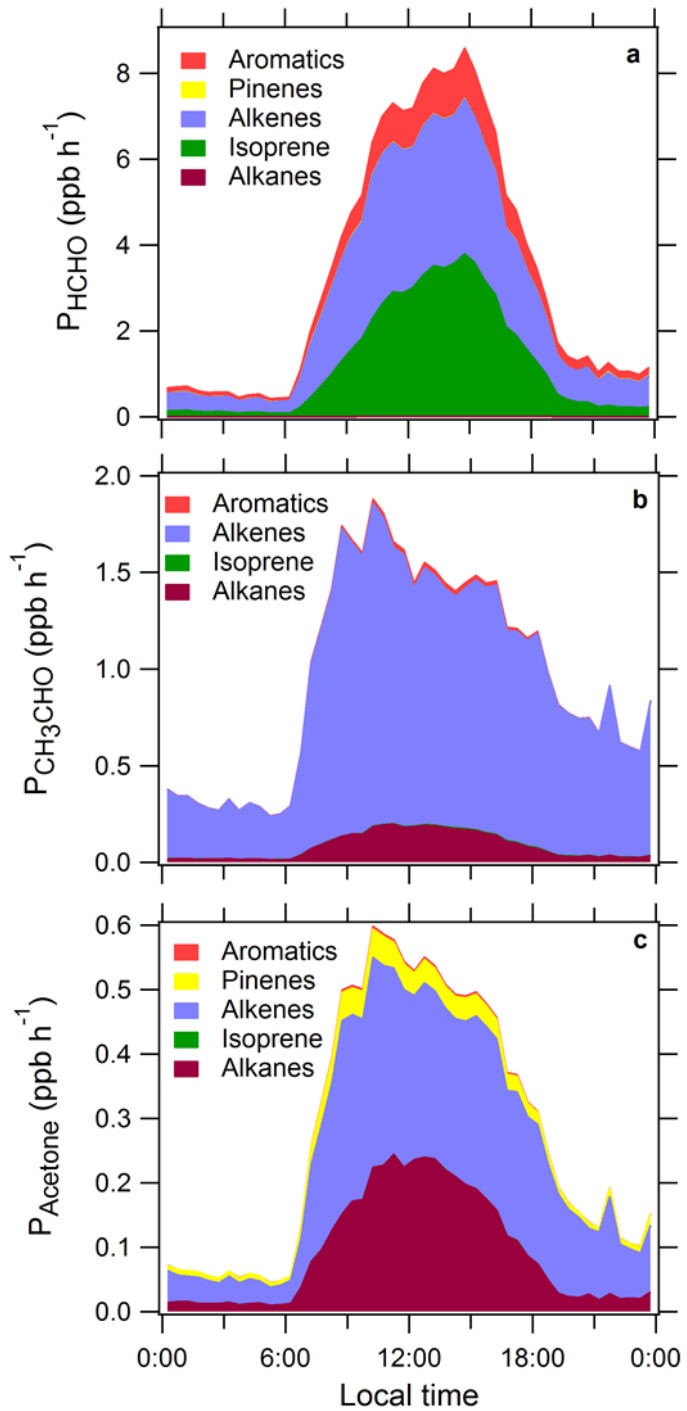

Figure 8. Averaged production of (a) formaldehyde, (b) acetaldehyde and (c) acetone during the full control period in the simulation of M4.

alkenes and isoprene were well matched, accounting for 39.7 and $37.5 \%$ of the total of averaged HCHO production, respectively (listed in Table S4).

Acetaldehyde production was found to be dominated by alkene oxidation $(91 \%)$ and the contributions of alkanes and aromatics were minor (7 and $1 \%$, respectively). Usually the dominant secondary $\mathrm{CH}_{3} \mathrm{CHO}$ source is from alkane oxidation (ethane, $n$-butane, $i$-butane) via the reaction of the C2H5O2 peroxy radical (Carter, 1990; Sommariva et al., 2008). But Sommariva et al. (2011) found that in urban plumes in the northeastern US, propene and other alkenes significantly contributed to the formation of acetaldehyde via the reaction of the HYPROPO alkoxy radical, especially in more fresh air masses during the first 2 days, when their contribution to acetaldehyde production is more important (up to $25 \%$ ). Then the role of $\mathrm{C} 3-\mathrm{C} 5$ alkenes decreases very quickly because of their high reactivity. Compared to urban plumes in the USA, air masses in Beijing are much fresher and closer to the emission sources. In Fig. 4 we can see that the majority of photochemical ages of air masses during the campaign are shorter than $40 \mathrm{~h}$, i.e., within 2 days. In this case, alkene oxidations become the most important processes for $\mathrm{CH} 3 \mathrm{CHO}$ formation.

For acetone, $60 \%$ of its production was from alkenes, $29 \%$ from alkanes, $10 \%$ from pinenes, and the remaining $1 \%$ was attributed to aromatics and isoprene. Secondary MEK was predominantly produced from the oxidation of alkanes (>95\%). The averaged results show that the oxidation of anthropogenic precursors is the dominant production pathway for secondary OVOCs in Beijing.

The NMHC oxidation for all OVOC compounds displays an obvious diurnal pattern with a peak at noon. Table 4 summarizes the averaged production rates and corresponding percentages of $\mathrm{HCHO}$ from different NMHC groups. For the full control period (M4), the pathway of isoprene oxidation accounted for up to $40 \%$ of the total production in the daytime, comparable to that of anthropogenic alkenes $(46 \%)$. The remaining $(13 \%)$ of $\mathrm{HCHO}$ production was attributed to aromatics. The contribution of biogenic sources decreased to $23 \%$ during the night and, accordingly, anthropogenic sources became the dominant contributor to $\mathrm{HCHO}$ production with a combined percentage of $76 \%$ (alkenes + aromatics). The differences in contributions between day and night are closely related to different diurnal patterns of anthropogenic and biogenic NMHCs.

\subsection{Changes in OVOCs responding to the control measures}

As indicated above, ambient concentrations of NMHCs were reduced by $30-45 \%$ due to the decrease in the city's emissions from 21 July to 27 August. Here, the effect of the reduced precursors together with other gas pollutants $(\mathrm{CO}, \mathrm{NO}$, $\mathrm{NO}_{2}$ and $\mathrm{O}_{3}$ ) on secondary OVOCs has been estimated using the box model.

Since the whole group of NMHCs were not measured by online GC-MS before the full control (3-20 July), the model scenario M5 ran with increased concentrations of alkanes, alkenes, aromatics and isoprene by $30,35,40$ and $15 \%$, respectively, according to the results from this work and a previous study on NMHCs by Wang et al. (2010a), in order to simulate the situation of the uncontrolled period. The concentrations of $\mathrm{NO}, \mathrm{NO}_{2}$ and $\mathrm{CO}$ in M5 were increased by 35, 25 and $17 \%$, while $\mathrm{O}_{3}$ was decreased by $16 \%$, taken from the observed changes in Wang et al. (2010c) and Chou et al. (2011). Then, the relative changes of secondary OVOCs responding to the control measures were determined by the difference between the model scenario of M5 (the uncontrolled period) and M4 (the full control period). 
Table 4. The average of production rates and corresponding percentages of formaldehyde from different precursors in the model simulations for the full control period (M4) and the scenario without the control measures (M5). All the values are presented as average \pm SD.

\begin{tabular}{|c|c|c|c|c|}
\hline & \multicolumn{2}{|c|}{ 09:00-17:00 LT } & \multicolumn{2}{|c|}{ 18:00-08:00 LT } \\
\hline & M4 & M5 & M4 & M5 \\
\hline$P_{\text {alkanes }}\left(\mathrm{ppbh}^{-1}\right)$ & $0.01 \pm 0.00$ & $0.01 \pm 0.00$ & $0.00 \pm 0.00$ & $0.00 \pm 0.00$ \\
\hline$P_{\text {alkenes }}\left(\mathrm{ppbh}^{-1}\right)$ & $3.08 \pm 1.65$ & $3.53 \pm 1.93$ & $0.75 \pm 0.72$ & $0.87 \pm 0.82$ \\
\hline$P_{\text {aromatics }}\left(\mathrm{ppbh}^{-1}\right)$ & $0.88 \pm 0.50$ & $1.00 \pm 0.58$ & $0.20 \pm 0.18$ & $0.23 \pm 0.20$ \\
\hline$P_{\text {isoprene }}\left(\mathrm{ppbh}^{-1}\right)$ & $2.77 \pm 1.76$ & $2.95 \pm 1.97$ & $0.35 \pm 0.45$ & $0.37 \pm 0.48$ \\
\hline$P_{\text {pinenes }}\left(\mathrm{ppbh}^{-1}\right)$ & $0.01 \pm 0.01$ & $0.01 \pm 0.01$ & $0.01 \pm 0.01$ & $0.01 \pm 0.01$ \\
\hline$P_{\text {total }}\left(\mathrm{ppbh}^{-1}\right)$ & $6.75 \pm 3.68$ & $7.50 \pm 4.22$ & $1.31 \pm 1.32$ & $1.47 \pm 1.46$ \\
\hline$P_{\text {alkanes }}(\%)$ & $0.1 \pm 0.1$ & $0.1 \pm 0.1$ & $0.2 \pm 0.2$ & $0.2 \pm 0.2$ \\
\hline$P_{\text {alkenes }}(\%)$ & $46.5 \pm 8.1$ & $48.0 \pm 8.3$ & $59.2 \pm 5.5$ & $60.3 \pm 5.5$ \\
\hline$P_{\text {aromatics }}(\%)$ & $13.2 \pm 1.9$ & $13.3 \pm 2.0$ & $16.8 \pm 2.6$ & $16.7 \pm 2.7$ \\
\hline$P_{\text {isoprene }}(\%)$ & $40.0 \pm 8.5$ & $38.4 \pm 8.6$ & $23.1 \pm 6.2$ & $22.1 \pm 6.0$ \\
\hline$P_{\text {pinenes }}(\%)$ & $0.2 \pm 0.1$ & $0.1 \pm 0.1$ & $0.8 \pm 0.6$ & $0.6 \pm 0.5$ \\
\hline
\end{tabular}

Table 5. The average of relative changes in OVOC concentrations from the scenario without pollution control measures (M5) to the control period (M4), compared to the corresponding values from the MLP network. Modelled change $(\%)=($ M4-M5)/M5 $\times 100.0$.

\begin{tabular}{lrr}
\hline Compounds & $\begin{array}{r}\text { Reduction from MLP } \\
\%\end{array}$ & $\begin{array}{r}\text { Modeled changes (\%) } \\
\text { average } \pm \text { SD }\end{array}$ \\
\hline Formaldehyde & -12.9 & $-11.1 \pm 2.4$ \\
Acetaldehyde & -15.8 & $-15.1 \pm 1.9$ \\
MVK + MACR & -11.3 & $-12.0 \pm 3.6$ \\
Acetone & -1.0 & $-12.8 \pm 1.4$ \\
MEK & -17.0 & $-13.3 \pm 0.1$ \\
\hline $\mathrm{OH}$ & & $11.2 \pm 5.5$ \\
$\mathrm{HO}_{2}$ & & $22.3 \pm 8.1$ \\
\hline
\end{tabular}

The modeled reductions in $\mathrm{HCHO}, \mathrm{CH}_{3} \mathrm{CHO}$ and MVK + MACR from M5 to M4 agree quite well with the corresponding results from the MLP network (given in Table 5 ), suggesting the measurable changes of those three species can be reasonably represented by the photochemical production from the oxidation of reduced precursors in the box model. For MEK, the relative change from the box model is $3.7 \%$ lower than the MLP results, which is likely related to the uncertainty of primary emissions. However, we found a large discrepancy of acetone changes in the two methods. The modeled changes $(12.8 \%)$ of acetone were much larger than the MLP result (1\%). As discussed in Sect. 3.2, there is no significant change in measured acetone during the full control period probably due to high backgrounds in the region. The change (12\%) of secondary production of acetone estimated by the model is relatively less important compared to transport in Beijing, it was covered by the high levels of acetone from a neighboring region. It seems difficult for the box model to evaluate such effects of background or transport.
The HCHO production rates from most of the precursors have been lowered during the full control period, but the ranks of different precursors did not change much (details listed in Table S4). Due to the emission restrictions the total production rate of $\mathrm{HCHO}$ decreased from 7.50 to $6.75 \mathrm{ppbh}^{-1}$, and the daytime productions of $\mathrm{HCHO}$ from the oxidation of alkenes, aromatics and isoprene were reduced by 13,12 and $6 \%$, respectively (from Table 4). The relative contribution of alkene oxidations in the daytime was decreased by $1.5 \%$ from the uncontrolled days (M5) to the full control period (M4) and, accordingly, the contribution of isoprene was increased by $1.7 \%$. Here, it should be noted that the relative importance of isoprene chemistry has been enhanced when the NMHC precursors from anthropogenic sources were reduced by $30-40 \%$. This would affect the relative potentials of reactive NMHCs for the formation of secondary pollutants (such as OVOCs and ozone).

\section{Conclusions}

In the summer of 2008 the pollution control measures implemented in Beijing provide a unique opportunity for studying how the primary and secondary air pollutants react to the reductions of anthropogenic emissions. Using a neural network analysis, we concluded that the emission controls taken in Beijing had a notable effect on reducing the ambient concentrations of formaldehyde, acetaldehyde, MEK and methanol. The influence of emission restrictions on OVOCs (except acetone) was found to be statistically significant when the variations due to meteorological conditions were excluded by the MLP network analysis. However, the effects of local emission controls on acetone seem to have been submerged in high background levels and no obvious changes were detected in acetone during the full control period. This highlights the complexity of secondary air pollutants (like 
OVOCs and $\mathrm{O}_{3}$ ), which needs to be treated as a regional issue.

The chemical production and degradation of OVOCs in Beijing under the emission control conditions have been determined quantitatively using a box model constrained with measurements of OVOCs precursors, gas pollutants and other physical parameters. The most important precursor of $\mathrm{HCHO}$ is isoprene, accounting for $30 \%$ of the total $\mathrm{HCHO}$ production. However, as a whole, the anthropogenic source is still the main contributor to secondary HCHO formation, with alkene oxidation accounting for $54 \%$ and aromatics for $15 \%$. Unlike $\mathrm{HCHO}$, anthropogenic NMHCs were found to play predominant roles on the chemical production of acetaldehyde, acetone and MEK. Approximately $90 \%$ of acetaldehyde production can be attributed to the oxidation of alkenes. Anthropogenic alkenes and alkanes contributed 60 and $29 \%$ of acetone formation, respectively, and biogenic precursors (pinenes) contributed the other $10 \%$. The relative changes in the modeled aldehydes and MVK + MACR due to the emission restrictions are shown to be consistent with the estimated results from the neural network, reflecting that the current chemical mechanisms can largely represent the realistic formation processes of aldehydes and $\mathrm{MVK}+\mathrm{MACR}$ in the high $\mathrm{NO}_{\mathrm{x}}$ urban conditions.

Compared to measurements of OVOCs, the box model overestimated the measured aldehydes by a factor of 1.4-1.7 without taking into consideration their loss on aerosols, and it was able to roughly explain diurnal variations of acetaldehyde most of time. The model-measurement discrepancy for aldehydes is mostly caused by missing sinks in the model, including physical dilution, transport and heterogeneous processes on the surface of aerosols. After adding the primary concentrations of ketones to the box model, the concentrations and diurnal cycles of MEK can be well represented by the model simulations. But the modeled changes of acetone become unimportant due to the high background and transport of acetone in Beijing and its surrounding areas

The analysis of the summer 2008 situation in Beijing improves our understanding of the complicated relationship between anthropogenic emissions and pollution levels of primary and secondary VOCs. The concentrations of NMHCs were reduced by $30-40 \%$ due to the emission controls. As vehicle emissions are the most important sources of VOCs in the city, the emission ratios of the traffic-related species $\left(\mathrm{C}_{2}\right.$ and $\mathrm{C}_{3}$ alkenes and light aromatics) in the controlled days are found to be fairly similar to the values before the controls and in other urban areas. The relatively similar emission ratios for the above hydrocarbons in cities will help in providing a general idea of the photochemical evolution of gas-phase organic carbons in urban plumes based on model simulations. As China is currently in the midst of a sustained effort to improve the air quality in its megacities, the results presented in this study can serve as a case for further understanding of the atmospheric chemistry not only for Beijing but also for large regions and as an important aid for policymakers considering ways to reduce pollution more efficiently in the long term.

\section{The Supplement related to this article is available online at doi:10.5194/acp-15-3045-2015-supplement.}

Acknowledgements. The authors wish to thank the entire CAREBEIJING 2008 team for their excellent support and collaboration, especially Chunsheng Zhao's group for processing metrological data at the PKU site. We also gratefully acknowledge Joost A. deGouw's group from the NOAA Earth System Research Laboratory for the provision of VOC data measured at the PKU site in 2005. This study was funded by the Natural Science Foundation for Outstanding Young Scholars (grant no. 41125018) and Natural Science Foundation key project (grant no. 41330635). This work was also supported by the National Natural Science Foundation of China (grant no. 41005067 and 41175112 ).

Edited by: A. B. Guenther

\section{References}

Andreae, M. O. and Merlet, P.: Emission of trace gases and aerosols from biomass burning, Global Biogeochem. Cy., 15, 955-966, 2001.

Bohn, B., Corlett, G. K., Gillmann, M., Sanghavi, S., Stange, G., Tensing, E., Vrekoussis, M., Bloss, W. J., Clapp, L. J., Kortner, M., Dorn, H.-P., Monks, P. S., Platt, U., PlassDülmer, C., Mihalopoulos, N., Heard, D. E., Clemitshaw, K. C., Meixner, F. X., Prevot, A. S. H., and Schmitt, R.: Photolysis frequency measurement techniques: results of a comparison within the ACCENT project, Atmos. Chem. Phys., 8, 53735391, doi:10.5194/acp-8-5373-2008, 2008.

Borbon, A., Gilman, J. B., Kuster, W. C., Grand, N., Chevaillier, S., Colomb, A., Dolgorouky, C., Gros, V., Lopez, M., SardaEsteve, R., Holloway, J., Stutz, J., Petetin, H., McKeen, S., Beekmann, M., Warneke, C., Parrish, D. D., and de Gouw, J. A.: Emission ratios of anthropogenic volatile organic compounds in northern mid-latitude megacities: observations versus emission inventories in Los Angeles and Paris, J. Geophys. Res.-Atmos., 118, 2041-2057, doi:10.1002/Jgrd.50059, 2013.

Carter, W. P. L.: A detailed mechanism for the gas-phase atmospheric reactions of organic compounds, Atmos. Environ. Part A, 24, 481-518, 1990.

Cermak, J. and Knutti, R.: Beijing Olympics as an aerosol field experiment, Geophys. Res. Lett., 36, L10806, doi:10.1029/2009g1038572, 2009.

Chan, C. K. and Yao, X.: Air pollution in mega cities in China, Atmos. Environ., 42, 1-42, 2008.

Chen, W. T., Shao, M., Lu, S. H., Wang, M., Zeng, L. M., Yuan, B., and Liu, Y.: Understanding primary and secondary sources of ambient carbonyl compounds in Beijing using the PMF model, Atmos. Chem. Phys., 14, 3047-3062, doi:10.5194/acp-14-30472014, 2014. 
Cheng, P., Cheng, Y. F., Lu, K. D., Su, H., Yang, Q., Zou, Y. K., Zhao, Y. R., Dong, H. B., Zeng, L. M., and Zhang, Y.: An online monitoring system for atmospheric nitrous acid (HONO) based on stripping coil and ion chromatography, J. Environ. Sci.-China, 25, 895-907, doi:10.1016/S1001-0742(12)60251-4, 2013.

Cheng, Y. F., Heintzenberg, J., Wehner, B., Wu, Z. J., Su, H., $\mathrm{Hu}$, M., and Mao, J. T.: Traffic restrictions in Beijing during the Sino-African Summit 2006: aerosol size distribution and visibility compared to long-term in situ observations, Atmos. Chem. Phys., 8, 7583-7594, doi:10.5194/acp-8-7583-2008, 2008.

Chou, C. C.-K., Tsai, C.-Y., Chang, C.-C., Lin, P.-H., Liu, S. C., and Zhu, T.: Photochemical production of ozone in Beijing during the 2008 Olympic Games, Atmos. Chem. Phys., 11, 9825-9837, doi:10.5194/acp-11-9825-2011, 2011

Dasgupta, P. K., Li, J. Z., Zhang, G. F., Luke, W. T., McClenny, W. A., Stutz, J., and Fried, A.: Summertime ambient formaldehyde in five US metropolitan areas: Nashville, Atlanta, Houston, Philadelphia, and Tampa, Environ. Sci. Technol., 39, 4767-4783, doi:10.1021/Es048327d, 2005.

de Gouw, J. and Warneke, C.: Measurements of volatile organic compounds in the earths atmosphere using proton-transferreaction mass spectrometry, Mass Spectrom. Rev., 26, 223-257, 2007.

de Gouw, J. A., Goldan, P. D., Warneke, C., Kuster, W. C., Roberts, J. M., Marchewka, M., Bertman, S. B., Pszenny, A. A. P., and Keene, W. C.: Validation of proton transfer reaction-mass spectrometry (PTR-MS) measurements of gas-phase organic compounds in the atmosphere during the New England Air Quality Study (NEAQS) in 2002, J. Geophys. Res.-Atmos., 108, 4682, doi:10.1029/2003JD003863, 2003.

de Gouw, J. A., Middlebrook, A. M., Warneke, C., Goldan, P. D., Kuster, W. C., Roberts, J. M., Fehsenfeld, F. C., Worsnop, D. R., Canagaratna, M. R., Pszenny, A. A. P., Keene, W. C., Marchewka, M., Bertman, S. B., and Bates, T. S.: Budget of organic carbon in a polluted atmosphere: Results from the New England Air Quality Study in 2002, J. Geophys Res.-Atmos, 110, D16305, doi:10.1029/2004JD005623, 2005.

Emmerson, K. M., Carslaw, N., and Pilling, M. J.: Urban atmospheric chemistry during the PUMA campaign 2: Radical budgets for $\mathrm{OH}, \mathrm{HO}_{2}$ and $\mathrm{RO}_{2}$, J. Atmos. Chem., 52, 165-183, doi:10.1007/s10874-005-1323-2, 2005.

Emmerson, K. M., Carslaw, N., Carslaw, D. C., Lee, J. D., McFiggans, G., Bloss, W. J., Gravestock, T., Heard, D. E., Hopkins, J., Ingham, T., Pilling, M. J., Smith, S. C., Jacob, M., and Monks, P. S.: Free radical modelling studies during the UK TORCH Campaign in Summer 2003, Atmos. Chem. Phys., 7, 167-181, doi:10.5194/acp-7-167-2007, 2007.

Finlayson-Pitts, B. J. and Pitts, J. N.: Chemistry of the Upper and Lower Atmosphere: Theory, Experiments, and Application, Academic Press, San Diego, California, 2000.

Goldan, P. D., Kuster, W. C., Williams, E., Murphy, P. C., Fehsenfeld, F. C., and Meagher, J.: Nonmethane hydrocarbon and oxy hydrocarbon measurements during the 2002 New England Air Quality Study, J. Geophys. Res.-Atmos., 109, D21309, doi:10.1029/2003JD004455, 2004.

Grosjean, D., Grosjean, E., and Moreira, L. F. R.: Speciated ambient carbonyls in Rio de Janeiro, Brazil, Environ. Sci. Technol., 36, 1389-1395, 2002.
Huang, X. F., He, L. Y., Hu, M., Canagaratna, M. R., Sun, Y., Zhang, Q., Zhu, T., Xue, L., Zeng, L. W., Liu, X. G., Zhang, Y. H., Jayne, J. T., Ng, N. L., and Worsnop, D. R.: Highly time-resolved chemical characterization of atmospheric submicron particles during 2008 Beijing Olympic Games using an Aerodyne HighResolution Aerosol Mass Spectrometer, Atmos. Chem. Phys., 10, 8933-8945, doi:10.5194/acp-10-8933-2010, 2010.

Jayne, J. T., Worsnop, D. R., Kolb, C. E., Swartz, E., and Davidovits, P.: Uptake of gas-phase formaldehyde by aqueous acid surfaces, J. Phys. Chem., 100, 8015-8022, doi:10.1021/jp953196b, 1996.

Karl, T., Harley, P., Emmons, L., Thornton, B., Guenther, A., Basu, C., Turnipseed, A., and Jardine, K.: Efficient Atmospheric Cleansing of Oxidized Organic Trace Gases by Vegetation, Science, 330, 816-819, doi:10.1126/science.1192534, 2010.

Li, X., Rohrer, F., Brauers, T., Hofzumahaus, A., Lu, K., Shao, M., Zhang, Y. H., and Wahner, A.: Modeling of HCHO and CHO$\mathrm{CHO}$ at a semi-rural site in southern China during the PRIDEPRD2006 campaign, Atmos. Chem. Phys., 14, 12291-12305, doi:10.5194/acp-14-12291-2014, 2014.

Li, Y., Shao, M., Lu, S. H., Chang, C. C., and Dasgupta, P. K.: Variations and sources of ambient formaldehyde for the 2008 Beijing Olympic games, Atmos. Environ., 44, 2632-2639, doi:10.1016/j.atmosenv.2010.03.045, 2010.

Lindinger, W., Hansel, A., and Jordan, A.: On-line monitoring of volatile organic compounds at pptv levels by means of protontransfer-reaction mass spectrometry (PTR-MS) - medical applications, food control and environmental research, Int. J. Mass Spectrom., 173, 191-241, 1998.

Liu, P. F., Zhao, C. S., Göbel, T., Hallbauer, E., Nowak, A., Ran, L., Xu, W. Y., Deng, Z. Z., Ma, N., Mildenberger, K., Henning, S., Stratmann, F., and Wiedensohler, A.: Hygroscopic properties of aerosol particles at high relative humidity and their diurnal variations in the North China Plain, Atmos. Chem. Phys., 11, 34793494, doi:10.5194/acp-11-3479-2011, 2011.

Liu, P. F., Zhao, C. S., Göbel, T., Hallbauer, E., Nowak, A., Ran, L., Xu, W. Y., Deng, Z. Z., Ma, N., Mildenberger, K., Henning, S., Stratmann, F., and Wiedensohler, A.: Hygroscopic properties of aerosol particles at high relative humidity and their diurnal variations in the North China Plain, Atmos. Chem. Phys., 11, 34793494, doi:10.5194/acp-11-3479-2011, 2011.

Liu, X. G., Li, J., Qu, Y., Han, T., Hou, L., Gu, J., Chen, C., Yang, Y., Liu, X., Yang, T., Zhang, Y., Tian, H., and Hu, M.: Formation and evolution mechanism of regional haze: a case study in the megacity Beijing, China, Atmos. Chem. Phys., 13, 4501-4514, doi:10.5194/acp-13-4501-2013, 2013.

Liu, Y., Shao, M., Zhang, J., Fu, L. L., and Lu, S. H.: Distributions and source apportionment of ambient volatile organic compounds in Beijing city, China, J. Environ. Sci. Heal. A, 40, 1843 1860, 2005.

Liu, Y., Shao, M., Kuster, W. C., Goldan, P. D., Li, X. H., Lu, S. H., and de Gouw, J. A.: Source identification of reactive hydrocarbons and oxygenated VOCs in the summertime in Beijing, Environ. Sci. Technol., 43, 75-81, 2009.

Lu, K. D., Rohrer, F., Holland, F., Fuchs, H., Bohn, B., Brauers, T., Chang, C. C., Häseler, R., Hu, M., Kita, K., Kondo, Y., Li, X., Lou, S. R., Nehr, S., Shao, M., Zeng, L. M., Wahner, A., Zhang, Y. H., and Hofzumahaus, A.: Observation and modelling of $\mathrm{OH}$ and $\mathrm{HO}_{2}$ concentrations in the Pearl River Delta 2006: 
a missing $\mathrm{OH}$ source in a VOC rich atmosphere, Atmos. Chem. Phys., 12, 1541-1569, doi:10.5194/acp-12-1541-2012, 2012.

Lu, K. D., Hofzumahaus, A., Holland, F., Bohn, B., Brauers, T., Fuchs, H., Hu, M., Häseler, R., Kita, K., Kondo, Y., Li, X., Lou, S. R., Oebel, A., Shao, M., Zeng, L. M., Wahner, A., Zhu, T., Zhang, Y. H., and Rohrer, F.: Missing $\mathrm{OH}$ source in a suburban environment near Beijing: observed and modelled $\mathrm{OH}$ and $\mathrm{HO}_{2}$ concentrations in summer 2006, Atmos. Chem. Phys., 13, 1057-1080, doi:10.5194/acp-13-1057-2013, 2013.

Lu, K. D., Rohrer, F., Holland, F., Fuchs, H., Brauers, T., Oebel, A., Dlugi, R., Hu, M., Li, X., Lou, S. R., Shao, M., Zhu, T., Wahner, A., Zhang, Y. H., and Hofzumahaus, A.: Nighttime observation and chemistry of $\mathrm{HO}_{\mathrm{X}}$ in the Pearl River Delta and Beijing in summer 2006, Atmos. Chem. Phys., 14, 4979-4999, doi:10.5194/acp-14-4979-2014, 2014

Lu, S., Liu, Y., Shao, M., and Huang, S.: Chemical speciation and anthropogenic sources of ambient volatile organic compounds during summer in Beijing City, Frontiers of Environmental Science \& Engineering, 1, 1-6, 2007.

Lyapustin, A., Smirnov, A., Holben, B., Chin, M., Streets, D. G., Lu, Z., Kahn, R., Slutsker, I., Laszlo, I., Kondragunta, S., Tanre, D., Dubovik, O., Goloub, P., Chen, H. B., Sinyuk, A., Wang, Y., and Korkin, S.: Reduction of aerosol absorption in Beijing since 2007 from MODIS and AERONET, Geophys. Res. Lett., 38, doi:10.1029/2011gl047306, 2011.

Mason, S. A., Field, R. J., Yokelson, R. J., Kochivar, M. A., Tinsley, M. R., Ward, D. E., and Hao, W. M.: Complex effects arising in smoke plume simulations due to inclusion of direct emissions of oxygenated organic species from biomass combustion, J. Geophys. Res.-Atmos., 106, 12527-12539, 2001.

Pang, X. B. and Mu, Y. J.: Seasonal and diurnal variations of carbonyl compounds in Beijing ambient air, Atmos. Environ., 40, 6313-6320, 2006.

Park, J.-H., Goldstein, A. H., Timkovsky, J., Fares, S., Weber, R., Karlik, J., and Holzinger, R.: Active atmosphere-ecosystem exchange of the vast majority of detected volatile organic compounds, Science, 341, 643-647, doi:10.1126/science.1235053, 2013.

Parrish, D. D. and Zhu, T.: Clean air for megacities, Science, 326, 674-675, doi:10.1126/science.1176064, 2009.

Riemer, N., West, M., Zaveri, R. A., and Easter, R. C.: Simulating the evolution of soot mixing state with a particleresolved aerosol model, J. Geophys. Res.-Atmos., 114, D09202, doi:10.1029/2008jd011073, 2009.

Rohrer, F. and Berresheim, H.: Strong correlation between levels of tropospheric hydroxyl radicals and solar ultraviolet radiation, Nature, 442, 184-187, doi:10.1038/nature04924, 2006.

Rohrer, F., Lu, K., Hofzumahaus, A., Bohn, B., Brauers, T., Chang, C.-C., Fuchs, H., Haseler, R., Holland, F., Hu, M., Kita, K., Kondo, Y., Li, X., Lou, S., Oebel, A., Shao, M., Zeng, L., Zhu, T., Zhang, Y., and Wahner, A.: Maximum efficiency in the hydroxyl-radical-based self-cleansing of the troposphere, Nat. Geosci., 7, 559-563, doi:10.1038/ngeo2199, 2014.

Saunders, S. M., Jenkin, M. E., Derwent, R. G., and Pilling, M. J.: Protocol for the development of the Master Chemical Mechanism, MCM v3 (Part A): tropospheric degradation of nonaromatic volatile organic compounds, Atmos. Chem. Phys., 3, 161-180, doi:10.5194/acp-3-161-2003, 2003.
Schauer, J. J., Kleeman, M. J., Cass, G. R., and Simoneit, B. R. T. Measurement of emissions from air pollution sources. 2. C1 through C-30 organic compounds from medium duty diesel trucks, Environ. Sci. Technol., 33, 1578-1587, 1999.

Schauer, J. J., Kleeman, M. J., Cass, G. R., and Simoneit, B. R. T.: Measurement of emissions from air pollution sources. 5. C-1-C32 organic compounds from gasoline-powered motor vehicles, Environ. Sci. Technol., 36, 1169-1180, 2002.

Shao, M., Wang, B., Lu, S. H., Liu, S. C., and Chang, C. C.: Trends in summertime non-methane hydrocarbons in Beijing city, 20042009, IGACtivities Newsletter, 42, 18-25, 2009.

Shao, M., Wang, B., Lu, S. H., Yuan, B., and Wang, M.: Effects of Beijing Olympics control measures on reducing reactive hydrocarbon species, Environ. Sci. Technol., 45, 514-519, doi:10.1021/es102357t, 2011.

Singh, H., Chen, Y., Staudt, A., Jacob, D., Blake, D., Heikes, B., and Snow, J.: Evidence from the Pacific troposphere for large global sources of oxygenated organic compounds, Nature, 410, 1078-1081, 2001.

Singh, H., O'Hara, D., Herlth, D., Sachse, W., Blake, D. R., Bradshaw, J. D., Kanakidou, M., and Crutzen, P. J.: Acetone in the atmosphere: distribution, sources, and sinks, J. Geophys. Res.Atmos., 99, 1805-1819, 1994.

Sommariva, R., Trainer, M., de Gouw, J. A., Roberts, J. M., Warneke, C., Atlas, E., Flocke, F., Goldan, P. D., Kuster, W. C., Swanson, A. L., and Fehsenfeld, F. C.: A study of organic nitrates formation in an urban plume using a Master Chemical Mechanism, Atmos. Environ., 42, 5771-5786, doi:10.1016/j.atmosenv.2007.12.031, 2008.

Sommariva, R., de Gouw, J. A., Trainer, M., Atlas, E., Goldan, P. D., Kuster, W. C., Warneke, C., and Fehsenfeld, F. C.: Emissions and photochemistry of oxygenated VOCs in urban plumes in the Northeastern United States, Atmos. Chem. Phys., 11, 70817096, doi:10.5194/acp-11-7081-2011, 2011.

Song, Y., Shao, M., Liu, Y., Lu, S. H., Kuster, W., Goldan, P., and Xie, S. D.: Source apportionment of ambient volatile organic compounds in Beijing, Environ. Sci. Technol., 41, 4348-4353, 2007.

Su, F.: Study on the Variation and Sources of Volatile Oragnic Compounds in Beijing, Ph.D. thesis, Peking University, 2003 (in Chinese).

Toda, K., Yunoki, S., Yanaga, A., Takeuchi, M., Ohira, S.-I., and Dasgupta, P. K.: Formaldehyde Content of Atmospheric Aerosol, Environ. Sci. Technol., 48, 6636-6643, doi:10.1021/es500590e, 2014.

UNEP: Independent Envrironmental Assessment: Beijing 2008 Olympic Games, UNEP, Nairobi, Kenya, 2009.

Wang, Q., Shao, M., Liu, Y., Kuster, W., Goldan, P., Li, X., Liu, Y., and $\mathrm{Lu}, \mathrm{S}$.: Impact of biomass burning on urban air quality estimated by organic tracers: Guangzhou and Beijing as cases, Atmos. Environ., 41, 8380-8390, 2007.

Wang, T. and Xie, S. D.: Assessment of traffic-related air pollution in the urban streets before and during the 2008 Beijing Olympic Games traffic control period, Atmos. Environ., 43, 5682-5690, doi:10.1016/j.atmosenv.2009.07.034, 2009.

Wang, M., Zhu, T., Zheng, J., Zhang, R. Y., Zhang, S. Q., Xie, X. X., Han, Y. Q., and Li, Y.: Use of a mobile laboratory to evaluate changes in on-road air pollutants during the Beijing 
2008 Summer Olympics, Atmos. Chem. Phys., 9, 8247-8263, doi:10.5194/acp-9-8247-2009, 2009a.

Wang, X., Westerdahl, D., Chen, L. C., Wu, Y., Hao, J. M., Pan, X. C., Guo, X. B., and Zhang, K. M.: Evaluating the air quality impacts of the 2008 Beijing Olympic Games: on-road emission factors and black carbon profiles, Atmos. Environ., 43, 4535-4543, doi:10.1016/j.atmosenv.2009.06.054, 2009b.

Wang, B., Shao, M., Lu, S. H., Yuan, B., Zhao, Y., Wang, M., Zhang, S. Q., and Wu, D.: Variation of ambient non-methane hydrocarbons in Beijing city in summer 2008, Atmos. Chem. Phys., 10, 5911-5923, doi:10.5194/acp-10-5911-2010, 2010a.

Wang, S. X., Zhao, M., Xing, J., Wu, Y., Zhou, Y., Lei, Y., He, K. B., Fu, L. X., and Hao, J. M.: Quantifying the air pollutants emission reduction during the 2008 Olympic Games in Beijing, Environ. Sci. Technol., 44, 2490-2496, doi:10.1021/Es9028167, 2010 b.

Wang, T., Nie, W., Gao, J., Xue, L. K., Gao, X. M., Wang, X. F., Qiu, J., Poon, C. N., Meinardi, S., Blake, D., Wang, S. L., Ding, A. J., Chai, F. H., Zhang, Q. Z., and Wang, W. X.: Air quality during the 2008 Beijing Olympics: secondary pollutants and regional impact, Atmos. Chem. Phys., 10, 7603-7615, doi:10.5194/acp-10-7603-2010, 2010c.

Wang, M., Shao, M., Chen, W., Yuan, B., Lu, S., Zhang, Q., Zeng, L., and Wang, Q.: A temporally and spatially resolved validation of emission inventories by measurements of ambient volatile organic compounds in Beijing, China, Atmos. Chem. Phys., 14, 5871-5891, doi:10.5194/acp-14-5871-2014, 2014.

Wang, Z. B., Hu, M., Yue, D. L., Zheng, J., Zhang, R. Y., Wiedensohler, A., Wu, Z. J., Nieminen, T., and Boy, M.: Evaluation on the role of sulfuric acid in the mechanisms of new particle formation for Beijing case, Atmos. Chem. Phys., 11, 12663-12671, doi:10.5194/acp-11-12663-2011, 2011.

Warneke, C., McKeen, S. A., de Gouw, J. A., Goldan, P. D., Kuster, W. C., Holloway, J. S., Williams, E. J., Lerner, B. M., Parrish, D. D., Trainer, M., Fehsenfeld, F. C., Kato, S., Atlas, E. L., Baker, A., and Blake, D. R.: Determination of urban volatile organic compound emission ratios and comparison with an emissions database, J. Geophys. Res.-Atmos., 112, D10S47, doi:10.1029/2006JD007930, 2007.

Witte, J. C., Schoeberl, M. R., Douglass, A. R., Gleason, J. F., Krotkov, N. A., Gille, J. C., Pickering, K. E., and Livesey, N.: Satellite observations of changes in air quality during the 2008 Beijing Olympics and Paralympics, Geophys. Res. Lett., 36, L17803, doi:10.1029/2009g1039236, 2009.

Worden, H. M., Cheng, Y. F., Pfister, G., Carmichael, G. R., Zhang, Q., Streets, D. G., Deeter, M., Edwards, D. P., Gille, J. C., and Worden, J. R.: Satellite-based estimates of reduced $\mathrm{CO}$ and $\mathrm{CO}_{2}$ emissions due to traffic restrictions during the 2008 Beijing Olympics, Geophys. Res. Lett., 39, L14802, doi:10.1029/2012g1052395, 2012.
Wu, Z. J., Hu, M., Lin, P., Liu, S., Wehner, B., and Wiedensohler, A.: Particle number size distribution in the urban atmosphere of Beijing, China, Atmos. Environ., 42, 7967-7980, doi:10.1016/j.atmosenv.2008.06.022, 2008.

Yokelson, R. J., Crounse, J. D., DeCarlo, P. F., Karl, T., Urbanski, S., Atlas, E., Campos, T., Shinozuka, Y., Kapustin, V., Clarke, A. D., Weinheimer, A., Knapp, D. J., Montzka, D. D., Holloway, J., Weibring, P., Flocke, F., Zheng, W., Toohey, D., Wennberg, P. O., Wiedinmyer, C., Mauldin, L., Fried, A., Richter, D., Walega, J., Jimenez, J. L., Adachi, K., Buseck, P. R., Hall, S. R., and Shetter, R.: Emissions from biomass burning in the Yucatan, Atmos. Chem. Phys., 9, 5785-5812, doi:10.5194/acp-9-5785-2009, 2009.

Yuan, B., Liu, Y., Shao, M., Lu, S., and Streets, D. G.: Biomass burning contributions to ambient VOCs species at a receptor site in the Pearl River Delta (PRD), China, Environ. Sci. Technol., 44, 4577-4582, doi:10.1021/es1003389, 2010a.

Yuan, B., Shao, M., Lu, S. H., and Wang, B.: Source profiles of volatile organic compounds associated with solvent use in Beijing, China, Atmos. Environ., 44, 1919-1926, doi:10.1016/j.atmosenv.2010.02.014, 2010b.

Yuan, B., Shao, M., de Gouw, J., Parrish, D. D., Lu, S., Wang, M., Zeng, L., Zhang, Q., Song, Y., Zhang, J., and Hu, M.: Volatile organic compounds (VOCs) in urban air: How chemistry affects the interpretation of positive matrix factorization (PMF) analysis, J. Geophys. Res.-Atmos., 117, D24302, doi:10.1029/2012jd018236, 2012.

Yuan, B., Warneke, C., Shao, M., and de Gouw, J. A.: Interpretation of volatile organic compound measurements by proton-transfer-reaction mass spectrometry over the deepwater horizon oil spill, Int. J. Mass. Spectrom., 358, 43-48, doi:10.1016/j.ijms.2013.11.006, 2014.

Zhang, Q., Jimenez, J. L., Worsnop, D. R., and Canagaratna, M.: A case study of urban particle acidity and its influence on secondary organic aerosol, Environ. Sci. Technol., 41, 3213-3219, doi:10.1021/Es061812j, 2007.

Zhang, X. Y., Wang, Y. Q., Lin, W. L., Zhang, Y. M., Zhang, X. C., Gong, S., Zhao, P., Yang, Y. Q., Wang, J. Z., Hou, Q., Zhang, X. L., Che, H. Z., Guo, J. P., and Li, Y.: Changes of atmospheric composition and optical properties over beijing 2008 Olympic Monitoring Campaign, Bull. Am. Meteorol. Soc., 90, 1633-1651, doi:10.1175/2009bams2804.1, 2009. 